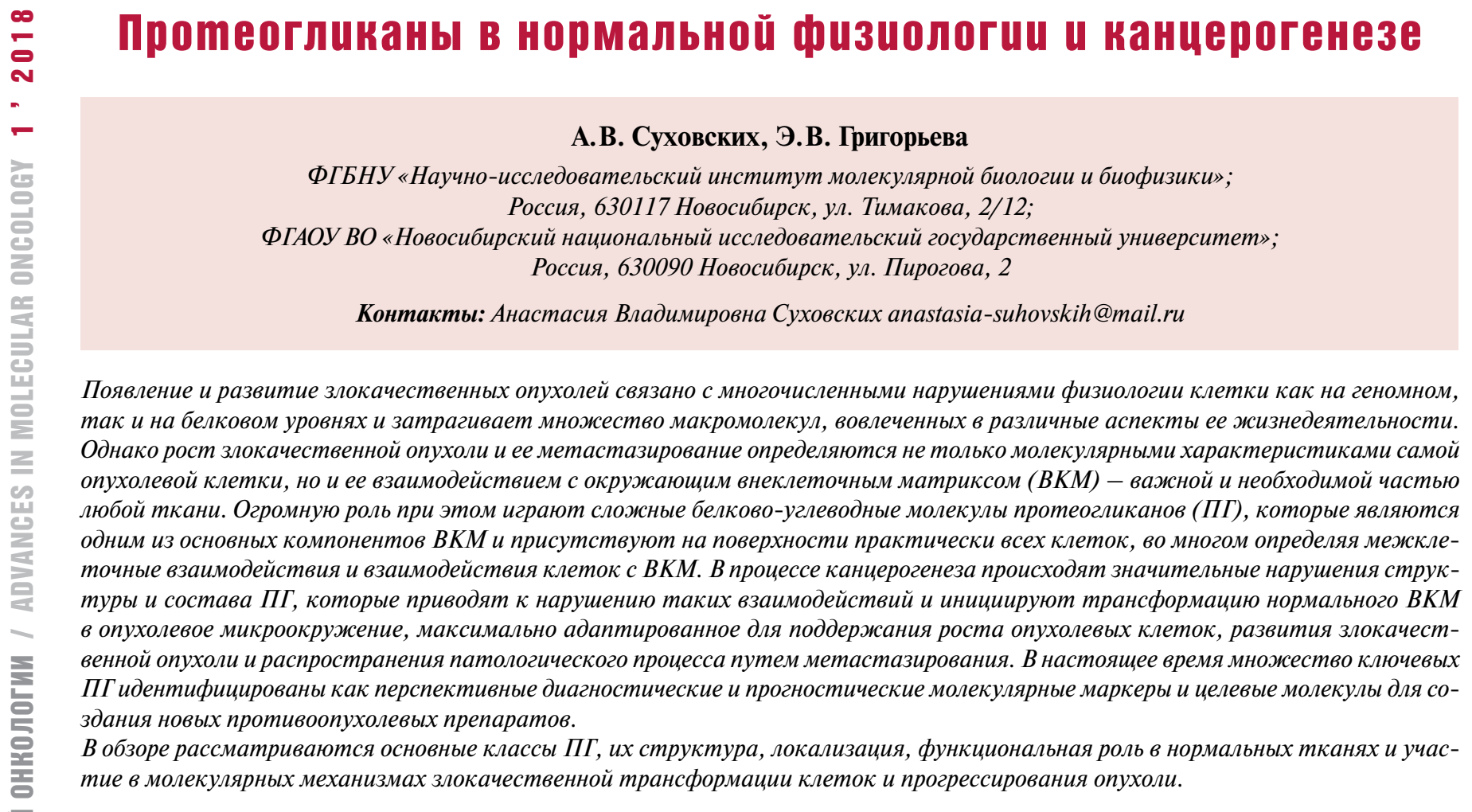

Ключевые слова: протеогликан, гликозаминогликан, гепарансульфат, хондроитинсульфат, внеклеточный матрикс, межклеточные взаимодействия, канцерогенез, опухолевое микроокружение, метастазирование

Для цитирования: Суховских А.В., Григорьева Э.В. Протеогликаны в нормальной физиологии и канцерогенезе. Успехи молекулярной онкологии 2018;5(1):8-25.

DOI: $10.17650 / 2313-805 X-2018-5-1-8-25$

\title{
Proteoglycans in normal physiology and carcinogenesis
}

\author{
A.V. Suhovskih, E.V. Grigorieva \\ Research Institute of Molecular Biology and Biophysics; 2/12 Timakova St., Novosibirsk 630117, Russia; \\ Novosibirsk State University; 2 Pirogova St., Novosibirsk 630090, Russia
}

Malignant transformation of any cell is associated with numerous physiological and morphological disorders at both genomic and protein levels, a variety of macromolecules being involved in. However, the tumour development and metastasis depends on not only the molecular characteristics of the tumour cell but also its interaction with the surrounding extracellular matrix (ECM), which is an important and necessary part of any tissue. An important role in this process belongs to the complex protein-carbohydrate molecules - proteoglycans (PG), which are one of the main component of ECM and cell surface of any tissue and are tightly involved in cell-cell and cell-matrix interactions and signaling. During carcinogenesis, significant changes in the PG structure and composition occur both at the surface of tumour cells and surrounding ECM, resulting in the transformation of normal ECM into a tumour microenvironment and deterioration of cell-cell and cell-matrix communication. Further, the tumorigenic niche contributes to active proliferation of the cancer cells, tumour development and metastasis. At present, many key PG are identified as possible diagnostic and prognostic molecular markers and target molecules for the creation of new antitumor drugs.

The review describes the main PG types, their structure, localisation, functional role in normal cell and tissue physiology and participation in molecular mechanisms of carcinogenesis.

Key words: proteoglycan, glycosaminoglycan, heparansulfate, chondroitinsulfate, extracellular matrix, cell-cell and cell-matrix interactions, carcinogenesis, tumour microenvironment, metastasis

For citation: Suhovskih A.V., Grigorieva E.V. Proteoglycans in normal physiology and carcinogenesis. Uspekhi molekulyarnoy onkologii $=$ Advances in Molecular Oncology 2018;5(1):8-25. 


\section{Введение}

В настоящее время, несмотря на интенсивные исследования, причины возникновения злокачественных опухолей и молекулярные механизмы канцерогенеза остаются недостаточно изученными. Известно, что этот процесс связан с функционированием множества сигнальных путей с участием различных молекул, состав, структура и экспрессия которых в процессе злокачественной трансформации клеток и тканей подвергаются значительным изменениям, что во многом определяет инициацию и развитие патологического процесса. Наряду с активно изучаемыми макромолекулами нуклеиновых кислот, белков, полисахаридов и липидов, значительную роль в физиологии клеток и тканей и их злокачественной трансформации играют также белково-углеводные молекулы, называемые протеогликанами (ПГ).

\section{Протеогликаны, гликозаминогликаны,}

\section{uх структура u классификация}

ПГ являются сложными белково-углеводными молекулами, состоящими из корового белка и ковалентно присоединенных к нему углеводных цепей гликозаминогликанов (ГАГ) [1]. Они представляют собой отдельный класс биологических макромолекул, принципиально отличающихся от гликопротеинов именно структурой их углеводных цепей (рис. 1).

Полисахаридные цепи ГАГ являются линейными полимерами, состоящими из повторяющихся дисахаридных субъединиц, каждая из которых включает гексозамин (D-глюкозамин или D-галактозамин) и уроновую кислоту (D-глюкуроновую или L-идуроновую). Каждый дисахарид может подвергаться избирательной модификации по различным положениям (сульфатирование по 2-, 3- и 6-О-положениям и ацетилирование/сульфатирование по N-положению), что приводит

\section{Гликопротеин / Glycoprotein}

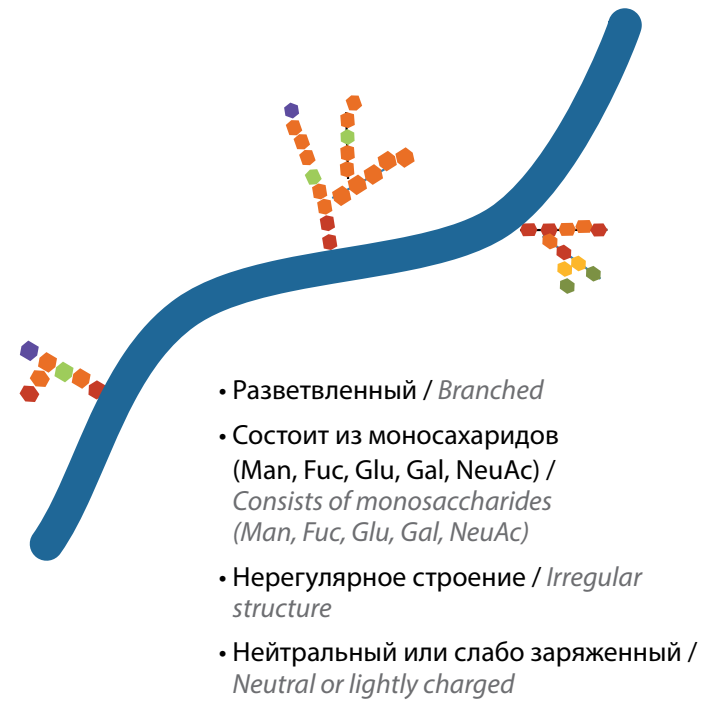

к высокому анионному заряду самих дисахаридов и образованной из них углеводной цепи ГАГ и молекулы ПГ в целом (рис. 2).

Степень сульфатирования молекулы ГАГ может варьировать в широких пределах (0-4 $\mathrm{SO}_{4}^{2-}$ групп/дисахарид) и определяет способность ГАГ/ПГ взаимодействовать с широким кругом различных биологически активных лигандов (в отличие от нейтральных молекул гликопротеинов) [2].

D-глюкозамин, D-галактозамин, D-глюкуроновая и L-идуроновая кислоты, галактоза являются исходными биосинтетическими блоками для построения всех молекул ГАГ, и в зависимости от строения дисахарида, входящего в состав углеводной цепи, ГАГ делят на следующие классы: гепарин/гепарансульфаты (ГС), хондроитинсульфаты (ХС), дерматансульфаты (ДС), кератансульфаты и гиалуроновая кислота (рис. 3).

Структура и классификация ПГ исчерпывающе описаны в обзорах [3, 4].

\section{Строение гепарансульфатов}

ГС является одним из основных классов ГАГ. Его углеводные цепи состоят из $\mathrm{N}$-ацетилированного или N-сульфатированного D-глюкозамина (GlcNAc), который связан с D-глюкуроновой (GlcA) или L-идуроновой кислотой (IdoUA) [5]. Особой разновидностью ГС является гепарин, характеризующийся высокой степенью сульфатирования идуроновой кислоты (по 2 углероду (IdoA2S)) и N-сульфатированного глюкозамина (по 6 положению (GlcNS6S)). Степень сульфатирования гепарина намного выше, чем ГC, что делает гепарин самой заряженной из всех известных биомолекул, которая является широко используемым фармацевтическим антикоагулянтом.

\section{Протеогликан / Proteoglycan}

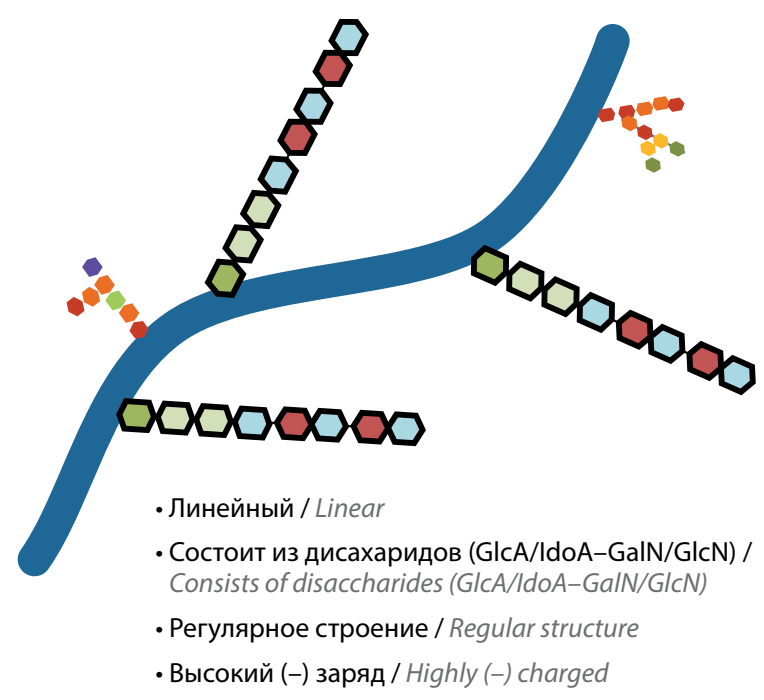

Рис. 1. Схематичное изображение молекул гликопротеина и протеогликана Fig. 1. Diagram of glycoprotein and proteoglycan molecules 


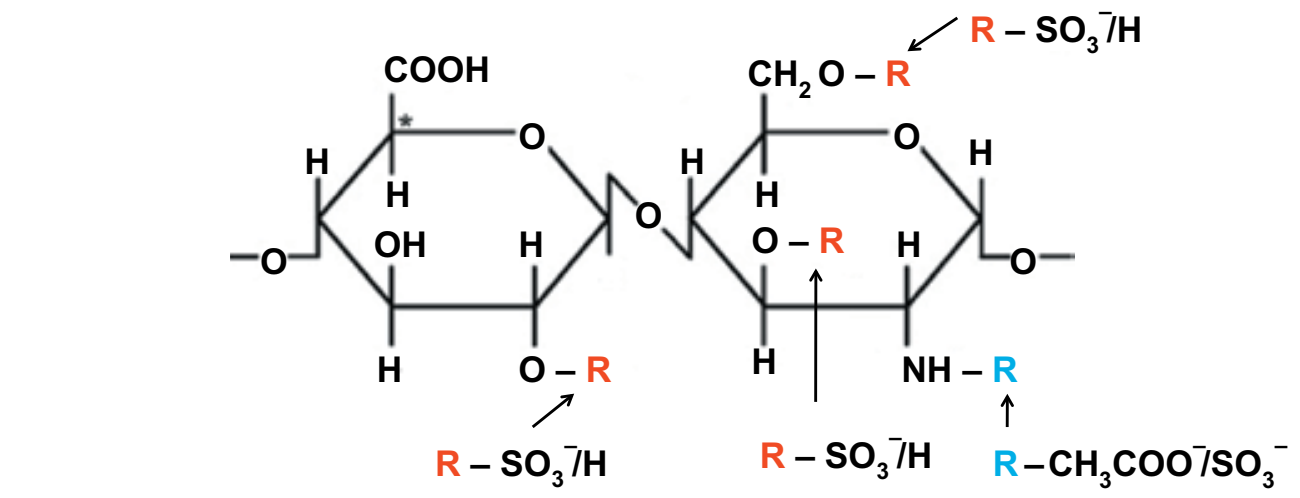

Уроновая кислота / Uronic acid Гексозамин / Hexosamine

Рис. 2. Схема возможных модификаций дисахарида. $R$ - гидроксильная (H), сульфатная ( $\left.\mathrm{SO}_{3}^{-}\right)$или ацетильная $\left(\mathrm{CH}_{3} \mathrm{COO}^{-}\right)$группа Fig. 2. Diagram of possible disaccharide modifications. $R-$ a hydroxyl $(\mathrm{H})$, sulfate $\left(\mathrm{SO}_{3}^{-}\right)$, or acetyl $\left(\mathrm{CH}_{3} \mathrm{COO}^{-}\right)$group

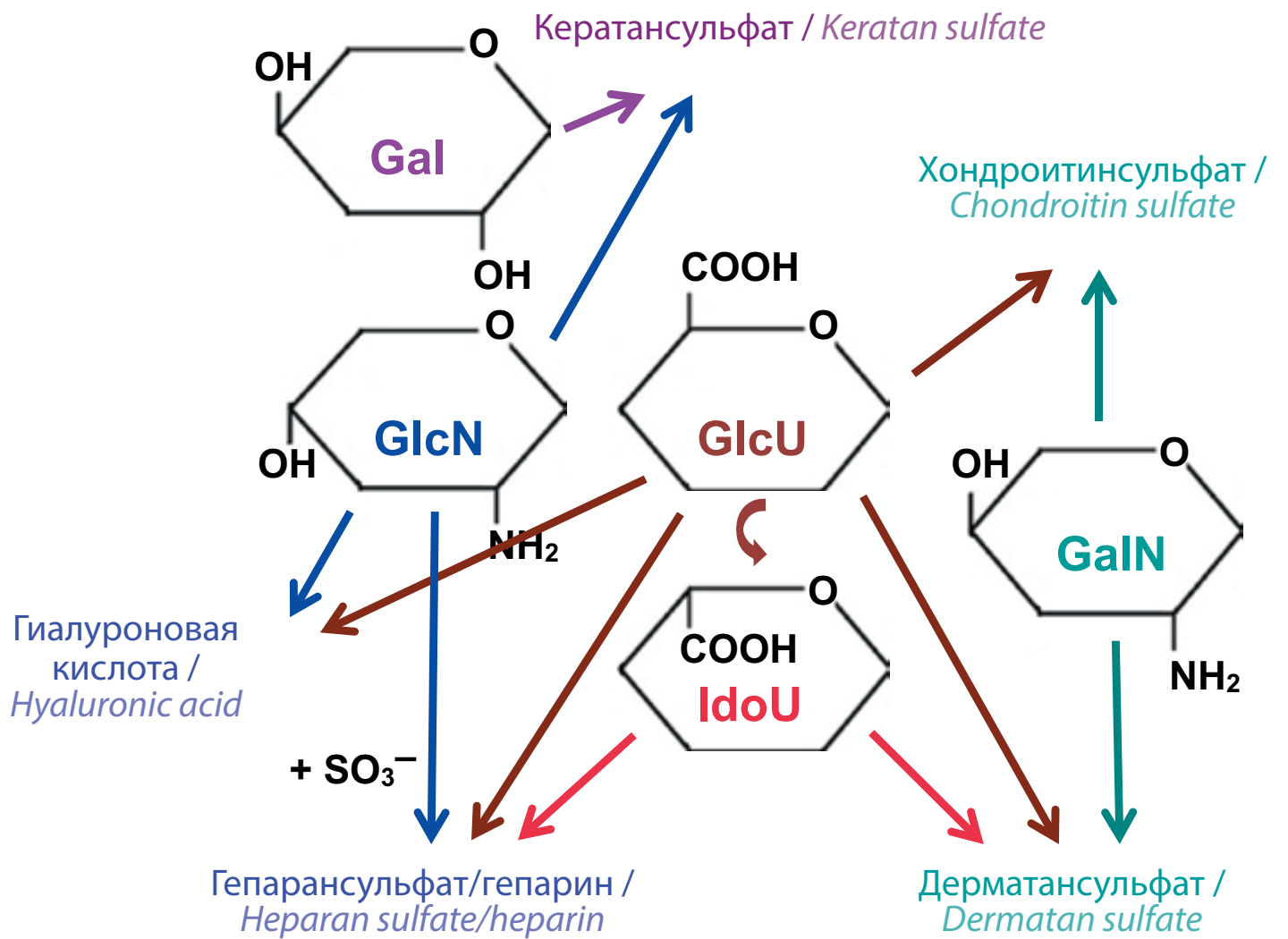

Рис. 3. Структура дисахаридов, образующих углеводные цепи гликозаминогликанов различных классов. Дисахариды могут быть O- и $N$-сульфатированы по разным положсениям. Gal - галактоза; GalN - галактозамин; GlcN - глюкозамин; GlcU - глюкуроновая кислота; IdoU - идуроновая кислота Fig. 3. Structure of disaccharides forming sugar chains of different classes of glycosaminoglycans. Disaccharides can be $O$ - and $N$-sulfated in different positions. Gal-galactose; GalN-galactosamine; GlcN-glucosamine; GlcU-glucuronic acid; IdoU - iduronic acid

\section{Строение хондроитинсульфатов} и дерматансульфатов

ХС содержат чередующиеся остатки глюкуроновой кислоты (GlcUA) и N-ацетилгалактозамина (GalNAc). Они значительно различаются по длине цепи и молекулярному весу: их вес колеблется в диапазоне от 5 до 70 кДа, даже при выделении из одного источника [6]. Подобно ГС, ХС могут быть N- и/или О-сульфатированы или ацетилированы по 2, 3, 4-му и/или 6-му положению и являются высокоанионными молекулами с гетерогенной структурой, а паттерн их сульфатирования напрямую влияет на их биологические функции.

ДС по своему составу совершенно идентичен молекуле ХC, однако содержит стереоизомер глюкуроновой кислоты (D-GlcUA) - идуроновую кислоту (L-IdoUA). Именно присутствие L-IdoUA-стереоизомера позволяет называть такую молекулу ДС, а не ХC. Глюкуроновая (GlcA) или идуроновая (IdoA) кислота 
в составе ДС может быть частично сульфатирована по C2-положению, а N-ацетилгалактозамин (GalNAc) по С4- или С6-положению [7].

\section{Строение кератансульфатов}

Основной дисахарид кератансульфатов состоит из $\mathrm{N}$-ацетилглюкозамина (GlcNAc) и галактозы, которые оба могут быть сульфатированы по С6-положению. Поэтому кератансульфат является единственным типом ГАГ, у которого отсутствует карбоксильная группа [8]. Молекулярный вес кератансульфата составляет от 5 до 25 кДа и сильно зависит от происхождения ткани. Самая высокая концентрация кератансульфата обнаружена в роговице. Кератансульфат является структурным компонентом нескольких ПГ - аггрекана, содержащегося в хрящах, и малых лейцин-богатых ПГ (люмикана, кератокана, фибромодулина). Помимо внеклеточного матрикса (ВКМ), кератансульфаты также обнаруживаются внутриклеточно в эозинофильных специфических гранулах и как часть клеточных трансмембранных белков, таких как CD44 и MUC1 [9].

Именно структура дисахаридов определяет тип углеводной цепи ГАГ, который, в свою очередь, отражается и в названии сложной белково-углеводной молекулы ПГ. Необходимо отметить, что на одном и том же коровом белке могут присутствовать одновременно различные цепи ГАГ, в таком случае название сложной молекулы ПГ определяется доминирующими цепями ГАГ, присутствующими на ее белковой коре.

\section{Локализация u функции протеогликанов}

\section{в нормальных тканях}

ПГ присутствуют практически во всех тканях всех живых организмов, начиная с трилобитов и заканчивая млекопитающими [10]. Основное место их локализации поверхность клеток и ВКМ. Именно их локализация и определяет основную функциональную роль ПГ в тканях млекопитающих - поддержание контактов клетки с окружающими ее клетками ВКМ [4]. Важность этой функции невозможно переоценить, ведь без поддержания тесных функциональных взаимосвязей невозможно существование любой ткани организма и его самого как целого.

ПГ принимают также активное участие в процессах дифференцировки и развития организма [11]. Их углеводные цепи могут специфически взаимодействовать с факторами роста, такими как факторы роста фибробластов FGF-1, FGF-2 и трансформирующие факторы роста (TGF), которые обладают гепаринсвязывающим доменом и активно вовлечены в процессы воспаления, заживления ран и развития опухолей [9].

Интересно, что существует преимущественная локализация различных классов ПГ в структуре ткани если гепарансульфат протеогликаны (ГСПГ) локализованы в основном на поверхности клеток и в составе базальной мембраны, то хондроитинсульфат/дерматансульфат-протеогликаны (ХСПГ/ДСПГ) в значительной степени сосредоточены во ВКМ (рис. 4).

\section{Протеогликаны клеточной поверхности}

На клеточной поверхности расположены в основном ГСПГ и представлены также некоторые ХСПГ (NG2/CSPG4, CD44) (см. рис. 4).

Синдеканы (syndecan, SDC) - трансмембранные ГСПГ (SDC1-SDC4), играющие роль в развитии, канцерогенезе, воспалении и регенерации тканей. Термин «синдекан» был введен M. Bernfield, чтобы обозначить класс ПГ, связывающих поверхность клетки с окружающим их ВКМ [12]. Коровые белки семейства синдеканов имеют внеклеточный, трансмембранный и внутриклеточный домены. Внеклеточный домен содержит сайты связывания цепей ГС и ХС, что говорит о гибридной природе синдеканов [13]. С-конец коровых белков всех синдеканов содержит уникальную последовательность (ЕFYA), которая связывает PDZ-содержащие белки, поддерживающие прочную связь трансмембранных белков с цитоскелетом, придавая прочность таким комплексам. Взаимодействие между синдеканами и актиновым цитоскелетом регулирует клеточную адгезию и миграцию.

Синдеканы выполняют множество биологических функций - связывают различные факторы роста (особенно за счет цепей ГС), создавая их градиенты во время развития; взаимодействуют с разнообразным набором лигандов, включая гликопротеины ВКМ, морфогены, цитокины, рецепторы факторов роста и интегрины [14]. Совместно с другими поверхностными ГСПГ синдеканы могут быть вовлечены в поглощение экзосом, принимают участие в регуляции концентрации внутриклеточного кальция и поддержании гомеостаза [15]. Интересно, что функция ПГ клеточной поверхности может быть изменена путем потери внеклеточного домена, что превращает связанные с мембраной корецепторы в молекулы, участвующие в паракринной регуляции [16].

Глипиканы (glypican, GPC) - ГСПГ, которые связаны с плазматической мембраной с помощью С-терминальной липидной части, представленной гликозилфосфатидилинозитолом (GPI, ГФИ-якорь) [17]. Отличие глипиканов от синдеканов состоит в том, что прикрепление углеводных цепей ГАГ (преимущественно ГС) происходит около трансмембранного домена. Данная особенность расположения углеводных цепей позволяет им охватывать большую поверхность плазматической мембраны, тем самым презентируя различные цитокины и факторы роста для их рецепторов. На сегодняшний день у млекопитающих обнаружено 6 членов семейства глипиканов (GPC1-GPC6), и роль этих ПГ в канцерогенезе различна. Глипиканы являются участниками нескольких сигнальных путей, включая Hedgehog (Hh) и FGF-2, a GPC3 связывается с белками Frizzled (тем самым активируя передачу сигналов через сигнальный путь Wnt) и участвует в передаче сигналов в тканях в качестве регулятора роста [18].

Нервный глиальный антиген $2(N G 2 / C S P G 4)$ - трансмембранный ПГ, несущий цепи ХС и имеющий 


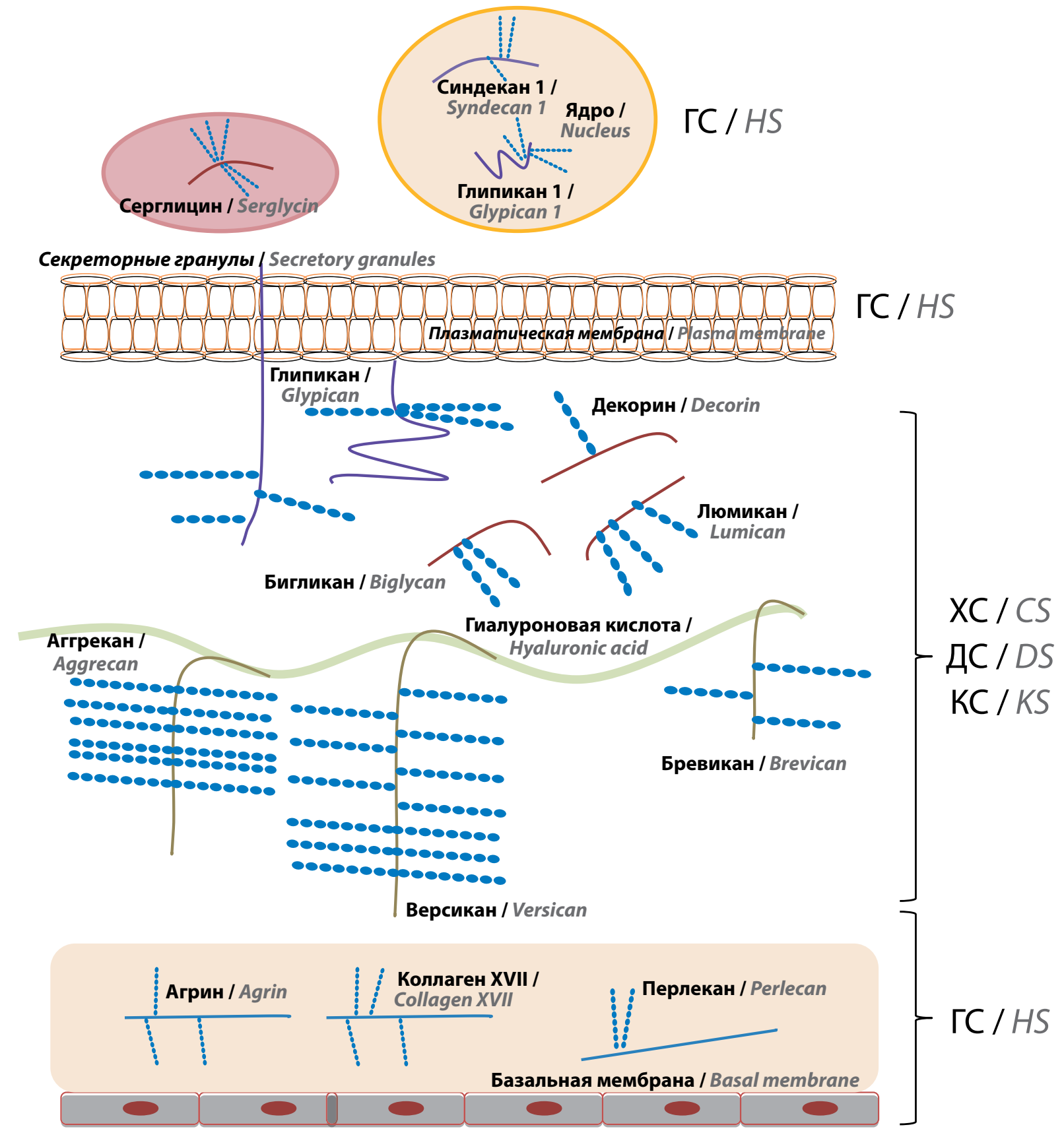

Рис. 4. Локализация протеогликанов в структуре тканей. ГС - гепарансульфат; ХС - хондроитинсульфат; ДС - дерматансульфат; КС - кератансульфат

Fig. 4. Localization of proteoglycans in tissue structure. HS - heparan sulfate; CS - chondroitin sulfate; DS - dermatan sulfate; KS - keratan sulfate

крупный внеклеточный домен, содержащий 3 субдомена, среди которых $\mathrm{N}$-терминальный домен содержит 2 ламининподобных повтора [19]. По-видимому, ламининподобные домены опосредуют связывание лигандов, межклеточные взаимодействия и взаимодействия клеток с окружающим ВКМ, а также взаимодействие с интегринами и рецепторами тирозинкиназ. Центральный субдомен содержит 15 тандемных повторов, называемых ХСПГ, с которыми связываются углеводные цепи ХС. Последние, в свою очередь, связывают коллаген V и VI типов, FGF и тромбоцитарный фактор роста
(PDGF), что опосредует взаимодействия данного ПГ c BKM.

NG2 экспрессируется многими клетками центральной нервной системы во время развития и дифференцировки и играет критическую роль в пролиферации и ангиогенезе [20]. В нормальной центральной нервной системе млекопитающих NG2 экспрессируется клетками-предшественниками олигодендроцитов, где он принимает активное участие во внутриклеточном сигналинге, взаимодействуя с цитоскелетом и влияя на миграцию клеток [21]. 
CD44. Рецептор клеточной поверхности CD44 широко известен как рецептор гиалуроновой кислоты и молекулярный маркер различных типов стволовых клеток [22]. Он является факультативным ХСПГ и может существовать как в виде белковой молекулы, так и ХСПГ, несущего углеводную цепь ХС [23]. В настоящий момент остается неясным, что именно определяет наличие либо отсутствие полисахаридной цепи ГАГ на коровом белке CD44 и ее взаимосвязь с функциональными свойствами интактной молекулы CD44.

\section{Протеогликаны внеклеточного матрикса}

ПГ и гиалуроновая кислота (наряду с коллагенами, фибронектином и эластином) составляют основу ВКМ, определяя как его структурные особенности, так и способность к взаимодействию с многочисленными лигандами и поддержанию целостности ткани. Основные ПГ ВКМ относятся преимущественно к классам ХСПГ и ДСПГ и в меньшей степени к кератансульфат-протеогликанам.

Галектаны (лектиканы) представляют собой отдельное семейство ХСПГ со структурным сходством как на геномном, так и на белковом уровне. ПГ этого семейства являются основными структурными элементами ВКМ, взаимодействуют с другими важными молекулами ВКМ, включая гиалуроновую кислоту и поверхностный клеточный рецептор CD44.

Это семейство включает в себя 4 разных гена, кодирующих версикан, аггрекан, бревикан и нейрокан. Общая особенность этих ПГ - их трехдоменная структура: N-концевой домен, который связывает гиалуроновую кислоту, центральный домен, несущий боковые цепи ГАГ, и С-концевая область, которая связывает лектины. На основании существования этой двойной активности на $\mathrm{N}$ - и С-концах молекулы был предложен термин «галектан», акроним для гиалурон- и лектинсвязывающих ПГ [1]. Функционирование галектанов регулируется путем протеолитического расщепления металлопротеиназами семейства ADAMTS (дезинтегрин и металлопротеиназа с фрагментом тромбоспондина) [24, 25].

Версикан (versican, $V C A N$ ) является ПГ ВКМ, который взаимодействует с клетками путем связывания с неинтегриновыми и интегриновыми рецепторами и с другими компонентами ВКМ, ассоциированными с поверхностью клетки. Он может существовать как в белковой форме, так и в форме ПГ (цепи ХС/ДС) [26].

Функциональные роли версикана многочисленны и сложны. Версикан участвует в регуляции клеточной адгезии, миграции и воспаления через взаимодействие его углеводных цепей ХС/ДС с цитокинами и факторами роста. Во время воспалительного ответа лейкоциты должны мигрировать из внутренних кровеносных сосудов в поврежденные окружающие ткани, при этом они сталкиваются с матриксом, сильно обогащенным версиканом, который, в свою очередь, способен взаимодействовать со многими рецепторами на по- верхности иммунных клеток, включая CD44, Р-селектин-гликопротеин-1 и Toll-подобные рецепторы [27]. В совокупности эти исследования показывают, что версикан играет центральную роль в воспалении и в результате может рассматриваться как потенциальная терапевтическая мишень.

Аггрекан (aggrecan, $A C A N$ ) имеет склонность к агрегации в большие супрамолекулярные комплексы вместе с гиалуроновой кислотой и связующими белками и является основным ПГ хрящевой ткани [28]. Эти крупные агрегаты образуют плотно упакованный гидратированный гель, объединенный в сеть армирующих коллагеновых фибрилл и других ПГ и гликопротеинов, который принципиально важен для осуществления функций суставов и играет ключевую роль в хрящевом и костном морфогенезе, функционируя как амортизатор, сопротивляясь сжимающим силам через поглощение воды или влияя на эластичность ткани [29].

Бревикан (brevican, $B C A N$ ) - один из самых важных ХСПГ центральной нервной системы. Он может существовать как полноразмерный ХСПГ или как частично расщепленный продукт без участка связывания ГАГ и $\mathrm{N}$-терминального домена. Бревикан вовлечен в множество физиологических и патофизиологических процессов пластичности в мозге [30]. Он локализован на поверхности нейронов, способствует образованию специфических типов ВКМ, таких как перинейрональные сети зрелой нервной ткани, и взаимодействует с тенасцином-R и фибулином-2. Показано, что бревикан вовлечен в развитие опухолей мозга, болезни Альцгеймера, повреждение и восстановление нервной ткани.

Малые лейцин-богатые ПГ. Малыми лейцин-богатыми ПГ (SLRP) обозначают класс ПГ, характеризующихся относительно небольшим белковым кором размером 36-42 кДа (по сравнению с более крупными аггрегирующими ПГ), центральная область которого состоит из богатых лейцином повторов (LRR) [4]. Это самое большое семейство ПГ, охватывающее 18 различных генов и многочисленные варианты сплайсированных форм. Малые лейцин-богатые ПГ являются биологически активными компонентами ВКМ, связанными с фибриллогенезом, клеточным ростом, апоптозом и ремоделированием тканей; поддерживают выживаемость клеток-предшественников межпозвоночных дисков в гипоксических условиях посредством активации специфических факторов, индуцируемых гипоксией [31]. Люмикан, кератокан, декорин, бигликан и остеоглицин присутствуют также в строме роговицы взрослых, а фибромодулин - в периферической лимбальной области, эпителий которой является источником стволовых клеток для роговицы. Декорин, бигликан, люмикан, фибромодулин были обнаружены в атеросклеротических бляшках, а также продемонстрировали свою роль в моделях атеросклероза на животных.

Функционирование SLRP также регулируется путем протеолитического расщепления металлопротеиназами [32]. 
Гиалуроновая кислота является неотъемлемым компонентом ВКМ любой ткани и играет важнейшую роль в ее организации и функциональной активности. В последнее время накапливается все больше данных о том, что гиалуроновая кислота - активный компонент ВKM, напрямую влияющий на функциональные характеристики других макромолекул и передачу сигнальной информации [33].

\section{Протеогликаны базальной мембраны}

Основными ПГ базальной мембраны являются перлекан, агрин и коллаген 18 (collagen XVIII). Все они относятся к классу ГСПГ и играют важную роль в структуре и функциональной активности базальной мембраны [34, 35].

Перлекан (ГСПГ 2) (perlecan/HSPG2) является основным компонентом базальных мембран, наряду с ламинином, коллагеном 4 и нидогеном/энтактином [36]. Он экспрессируется в широком спектре тканей, где регулирует разнообразные клеточные процессы, включая формирование костей, воспаление и ангиогенез, в первую очередь благодаря его способности взаимодействовать с различными лигандами и рецепторами тирозинкиназ.

Перлекан экспрессируется как в сосудистых, так и не в сосудистых тканях и преимущественно расположен на апикальной поверхности клетки и базальных мембранах [37]. В нативном состоянии он обладает проангиогенными свойствами, однако при частичном воздействии протеаз, высвобождаемых при ремоделировании и инвазии при развитии опухоли, С-концевой фрагмент перлекана - эндорепеллин - имеет противоположные эффекты, в отличие от исходной молекулы. Эндорепеллин является мощным ингибитором ангиогенеза, взаимодействуя одновременно с рецептором с тирозинкиназной активностью, активируемым сигнальным белком VEGF (VEGFR2), и интегрином $\alpha 2 \beta 1$ [4].

Углеводные ГС-цепи перлекана могут быть расщеплены гепараназой с высвобождением различных проангиогенных факторов.

Агрин. Структура ГСПГ агрина (agrin, $A G R N)$ гомологична структуре перлекана и содержит множество различных доменов. Агрин экпрессируется на высоком уровне в легких, почках и головном мозге, в то время как в скелетных мышцах и нормальной печени было обнаружено лишь небольшое количество агрина. K функциям агрина относится связывание различных факторов роста и цитокинов во внеклеточной среде [35].

Коллаген 18 (collagen XVIII, COL18A1) является ГСПГ и представляет собой гомотример, состоящий из 3 идентичных цепей $\alpha 1$ и 10 прерывающихся коллагеновых доменов, фланкированных 11 неколлагеновыми доменами на соответствующих $\mathrm{N}$ - и С-концах. Коллагеновые и неколлагеновые домены, по-видимому, различаются по своим функциям [38]. Коллаген 18 экспрессируется повсеместно в различных сосудистых и эпителиальных структурах базальной мембраны по всему организму.

\section{Функциональная роль протеогликанов \\ при канцерогенезе}

Злокачественная трансформация клеток практически всегда ассоциирована со значительными изменениями структуры, состава, локализации и функциональных характеристик ПГ, являющихся неотъемлемой частью как самих клеток, так и их микроокружения $[39,40]$.

Известно, что внеклеточные малые лейцин-богатые ПГ бигликан и декорин играют важную роль в процессах воспаления и аутофагии [41]. Декорин является провоспалительным агентом, регулирует активность макрофагов и секрецию цитокинов, супрессирует рост опухолей, ангиогенез и препятствует возникновению очагов метастазирования в различных моделях in vivo и in vitro [42]. Системная доставка белка декорина или локальная доставка аденовирусных векторов, экспрессирующих декорин, может ингибировать рост опухоли, влиять на рост метастазов опухоли в кости, ингибировать остеокластогенез и способствовать остеобластогенезу [43, 44].

Повышенная экспрессия версикана наблюдается в широком спектре злокачественных опухолей и ассоциирована как с рецидивированием, так и с плохими результатами лечения многих видов рака, в частности у пациентов с раком предстательной железы (РПЖ). Через отрицательно заряженные боковые цепи ХС и ДС версикан способен регулировать многие клеточные процессы, включая клеточную адгезию, пролиферацию, апоптоз, миграцию, ангиогенез, инвазию и метастазирование [45].

NG2/CSPG4 является прогностическим фактором и инструментом неинвазивной молекулярной диагностики благодаря тесной ассоциации со злокачественными новообразованиями, а также может быть терапевтической мишенью в некоторых типах опухолей [19].

Состав и структура ГСПГ подвергаются значительным изменениям в опухолях яичников и молочной железы человека [46, 47]; экспрессия синдекана 1, декорина и люмикана значительно изменяется в опухолях молочной железы [48], глипиканы вовлечены в процесс канцерогенеза в тканях легкого [49] и поджелудочной железы [50]; синдеканы участвуют в патогенезе лимфомы Ходжкина [51]; экспрессия перлекана и серглицина значительно снижается в клетках лимфомы Беркитта [52]; уровень экспрессии коллагена 18 ассоциируется с прогрессированием и прогнозом гепатоцеллюлярной карциномы [53], а в опухолях прямой кишки происходит одновременное снижение уровней экспрессии декорина и перлекана (в 2 раза) и повышение экспрессии бигликана и версикана (в 6 и 3 раза соответственно) [54]. ПГ глипиканы, агрин, версикан и декорин принимают активное участие в развитии злокачественных 
опухолей печени и прогрессии экспериментальных опухолей в системе in vitro [55].

Помимо количественных изменений в уровнях экспрессии различных ПГ, в процессе злокачественной трансформации происходят также качественные изменения, связанные с нарушением внутриклеточной и внутритканевой локализации ПГ [54]. Экспрессия люмикана повышается в строме, окружающей опухоли молочной железы человека, по сравнению с нормальной стромой, тогда как в аналогичных фибробластоподобных клетках стромы внутри или непосредственно рядом с опухолями молочной железы человека происходит снижение содержания декорина [56]. Экспрессия бигликана увеличена в строме опухолей поджелудочной железы по сравнению с нормальной панкреатической тканью и, как показано, ингибирует рост опухолевых клеток [57].

Необходимо отметить, что важной особенностью экспрессии и паттерна ПГ в нормальных клетках и тканях млекопитающих является их тканеспецифичность, впервые обнаруженная более 30 лет назад [58], хотя этот вопрос до сих пор остается малоизученным. Лишь в последнее время стали появляться данные, которые не только подтвердили эти результаты, но и показали тканеспецифичный характер изменений паттерна и уровней экспрессии основных ПГ при злокачественной трансформации клеток и тканей как на уровне их коровых белков [59], так и углеводных цепей, присутствующих на этих коровых белках [60]. В совокупности это приведет к появлению данных о специфическом составе и локализации различных ПГ, характерных для каждой ткани и классифицирующих определенный тип опухоли.

В силу вышесказанного, при изучении ПГ и их вовлеченности в процессы канцерогенеза представляется целесообразным проведение сравнительных исследований, связанных с развитием и прогрессией злокачественных опухолей различных типов. В следующих разделах мы приведем данные об участии ПГ в развитии тех типов опухолей, которые наиболее интенсивно изучаются и в нашей лаборатории [61-64].

\section{Протеогликаны в глиальных опухолях головного мозга}

Структурная и функциональная роль ПГ в возникновении и развитии злокачественных опухолей головного мозга подробно обсуждается в обзорах $[65,66]$. Наиболее значимую роль при раке этого типа (глиальные опухоли) играют ХСПГ/ДСПГ и кератансульфатпротеогликаны.

При анализе экспрессии различных индивидуальных ПГ прослеживается определенная тенденция - экспрессия большинства ПГ активируется в тканях глиом высокой степени злокачественности и коррелирует с плохим прогнозом течения заболевания, и только декорин является единственным ПГ, проявляющим антипролиферативное и антиопухолевое действие.
Показано, что избыточная экспрессия декорина подавляет рост клеток глиомы, а лечение экзогенным декорином ингибирует адгезию и миграцию клеток глиомы U87MG, снижая передачу сигналов через TGF- $\beta$ [67]. Эктопическая экспрессия декорина приводит к замедлению прогрессирования глиомы in vivo [68].

Повышенная экспрессия изоформ версикана во ВКМ играет роль в прогрессировании злокачественных глиом, способствуя адгезии и миграции опухолевых клеток, и этот эффект, по крайней мере частично, опосредуется участием версиканов V0/V1 [69]. Подавление экспрессии версикана V1 с помощью малых интерферирующих РНК приводит к значительному снижению пролиферации и миграции клеток глиомы, что поддерживает предположение о проканцерогенных эффектах версикана V1 в регуляции пролиферации и миграции опухолевых клеток при развитии глиобластомы [70].

Экспрессия NG2/CSPG4 также усиливается в глиомах и может стимулировать васкуляризацию опухоли. Наряду с передачей сигналов от факторов роста NG2 является рецептором клеточной поверхности для компонентов ВКМ и $\beta 1$-интегрина, и его активация вносит свой вклад в такие процессы, как пролиферация клеток, их подвижность и жизнеспособность [71]. Экспрессия NG2 в опухолях головного мозга у детей различается в зависимости от типа, и, в отличие от глиомы у взрослых, NG2 экспрессируется в опухолях более низкой степени злокачественности [72]. Кроме того, NG2-экспрессирующие клетки глиобластомы устойчивы к ионизирующему излучению и повреждениям ДНК, по-видимому, опосредуя резистентность опухолей к лучевой терапии путем индукции ферментов, поглощающих активные формы кислорода, что замедляет повреждение ДНК [73].

Экспрессия бревикана связана с дифференцировкой клеток глиомы и их адгезивными свойствами, а также подвижностью и ростом опухоли [74]. Бревикан способствует активации рецептора эпидермального фактора роста, увеличивает экспрессию молекул клеточной адгезии, способствует секреции фибронектина и накоплению его микрофибрилл на поверхности клетки. Кроме того, $\mathrm{N}$-концевой продукт расщепления бревикана, но не полный белок, ассоциируется с фибронектином в культивируемых клетках и клинических образцах глиомы [75].

Экспрессия CD44 заметно увеличивается при прогрессировании глиомы [76]. Вероятно, гиалуроновая кислота усиливает инвазию клеток глиомы в модельной системе in vitro именно через молекулярный механизм, включающий в себя взаимодействие гиалуроновой кислоты с CD44 [77].

Повышенная экспрессия серглицина в глиоме зависит от степени злокачественности опухоли, положительно коррелирует с инфильтрацией тучными клетками и ассоциирована с низкой выживаемостью пациентов [78].

Уровень экспрессии корового белка синдекана 1 повышен в тканях глиомы по сравнению с контрольной 
тканью и отрицательно ассоциирован со степенью злокачественности опухоли и прогнозом заболевания [79]. Злокачественные клетки глиомы экспрессируют также синдеканы 2, 3 и 4 [80].

Экспрессия глипикана 1 повышена в эндотелиальных клетках глиомы сосудов, что может способствовать ангиогенезу и устойчивости опухолей к лучевой терапии через FGF-2-опосредованный механизм [81]. Экспрессия глипикана 1 повышена также в ткани астроцитомы и олигодендроглиомы по сравнению с нетрансформированной тканью головного мозга и способствует усиленной передаче сигналов от FGF2 через рецептор FGFR1c [82].

\section{Протеогликаны в опухолях}

\section{предстательной железы}

В литературе есть детальные обзоры, касающиеся функциональной роли ПГ в развитии РПЖ [83]. Для этого типа эпителиальных опухолей наиболее значимые изменения происходят в экспрессии и локализации ГСПГ.

ГСПГ синдекан 1 является наиболее изученным при РПЖ, хотя единого мнения об экспрессии синдекана 1 в этом типе опухолей пока не существует. В нескольких работах показано снижение экспрессии синдекана 1 в опухолях по сравнению с нормальной тканью: экспрессия синдекана 1 не изменяется при доброкачественной гиперплазии и интраэпителиальной неоплазии предстательной железы, но значительно снижается в аденокарциномах и полностью исчезает в слабо дифференцированных опухолях [84]; пониженная экспрессия синдекана 1 ассоциирована с развитием низкодифференцированных опухолей и плохим прогнозом для пациентов, а нарушение в экспрессии и околоклеточной локализации синдекана 1 может быть сигналом к возникновению рецидива [85]; значительное снижение содержания синдекана 1 в различных областях опухоли положительно коррелирует с высоким значением суммы баллов по шкале Глисона и наличием регионарных метастазов [86]. В то же время повышенная экспрессия синдекана 1 наблюдается в гормононезависимых и метастатических опухолях предстательной железы по сравнению с доброкачественной гиперплазией и интраэпителиальной неоплазией [87] и не коррелирует с оценкой по шкале Глисона [88].

Экспрессия глипикана 1 в клетках РПЖ значительно повышается [64]. В настоящее время разрабатывается методика иммуноферментного анализа для оценки уровней глипикана 1 в нормальной ткани, доброкачественной гиперплазии и злокачественных опухолях предстательной железы, чтобы определить, может ли секретируемый глипикан 1 представлять клинически значимый биомаркер для диагностики РПЖ [89].

Уровень экспрессии глипикана 5 в опухолях предстательной железы, особенно в агрессивных, снижен по сравнению с нормальной тканью и тесно ассоциирован с повышенным уровнем в крови простатическо- го специфического антигена, высоким значением по шкале Глисона, стадией опухоли Т3 и метастазами в лимфатические узлы. Кроме того, низкая экспрессия глипикана 5 является независимым прогностическим фактором общей выживаемости больных РПЖ и может, таким образом, служить биомаркером диагностики и прогноза заболеваемости [90].

Перлекан экспрессируется на границах тканей, включая те, которые разделяют эпителий и соединительную ткань. Его экспрессия увеличивается вблизи участков инвазии первичных опухолей предстательной железы, преимущественно за счет того, что опухолевые клетки и группы стромальных клеток увеличивают продукцию перлекана в ответ на цитокины, присутствующие в микроокружении опухоли [91]. In vitro показано, что в регуляции экспрессии корового белка гена $H S P G 2$ участвует цитокин TNF- $\alpha$ (фактор некроза опухоли альфа), что говорит о возможном вовлечении перлекана в цитокинопосредованные реакции, влияющие на инвазию клеток РПЖ [91]. В опухолях предстательной железы уровни матриксной металлопротеиназы 7 и перлекана высоко коррелируют между собой, а ферментативная обработка перлекана матриксной металлопротеиназой 7, как это происходит в микроокружении инвазивных опухолей, является молекулярным переключателем для изменения поведения клеток РПЖ и благоприятствует их инвазии [92]. В сыворотке больных РПЖ обнаружен повышенный уровень фрагментов перлекана (причем большинство из домена IV) по сравнению с нормальной сывороткой, что указывает на его деградацию в процессе метастазирования и может служить одним из критериев инвазивного РПЖ [93].

Показано, что метастатические клетки РПЖ создают во ВКМ особую метастатическую нишу, изменяя фенотип местных стромальных клеток и сам ВКМ. В присутствии 2 метастатических клеточных линий РПЖ РC3 и DU145 экспрессия таких компонентов ВКМ, как малые лейцин-богатые ПГ (декорин, бигликан, люмикан и фибромодулин), в фибробластах значительно снижается. У животных, которым были трансплантированы совместные культуры метастатических клеток РПЖ и «активированные» фибробласт/остеобластподобные клетки, развивались более крупные опухоли по сравнению с животными, которым трансплантировали только метастатические опухолевые клетки [94].

Показано, что экспрессия декорина снижается в строме опухолей предстательной железы по сравнению с нормальной стромой, а низкие уровни декорина обычно считаются плохим прогностическим маркером РПЖ [83]. Эктопическая экспрессия декорина, обусловленная введением рекомбинантной аденовирусной конструкции в клеточные линии РC3 и DU145, приводила к ингибированию сигнального пути Wnt $\beta$ катенин, фактора роста эндотелия сосудов А и ингибировала миграцию опухолевых клеток. Инокуляция 
животным аденовируса, несущего ген декорина, в мышиной модели in vivo вызывает значительное ингибирование появления метастазов в кости, снижение опухолевой массы, числа остеокластов и увеличение выживаемости животных, что говорит о возможном использовании этого вектора как потенциального терапевтического агента для лечения метастазов в кости при РПЖ [95].

Данных об экспрессии люмикана в опухолях предстательной железы достаточно мало. Известно, что он экспрессируется в нормальной ткани предстательной железы и его экспрессия увеличивается при гиперплазии по сравнению с нормальной тканью [96]. Анализ in vitro показал, что люмикан ингибирует миграцию и инвазию метастатических клеток РПЖ, выделенных из лимфатического узла, кости и мозга. Более того, значительное увеличение инвазии клеток через брюшину наблюдалось у мышей, нокаутных по люмикану, что демонстрирует ограничительную роль люмикана, присутствующего во ВКМ, в отношении инвазии РПЖ. Увеличение экспрессии люмикана наблюдается в строме, окружающей первичные опухоли предстательной железы, играет ограничивающую роль в развитии рака и может быть ценным диагностическим и/или прогностическим маркером при РПЖ [97]. Существуют также данные о том, что люмикан может находиться внутриклеточно в секреторных гранулах эпителиальных клеток предстательной железы, и предполагается, что при такой локализации он может действовать как опухолевый супрессор [96].

Также из литературы известно, что при доброкачественной гиперплазии предстательной железы происходит накопление версикана [98], а его ингибирование может быть потенциальной терапевтической стратегией в комплексном лечении кастрационно-резистентного РПЖ [99].

В целом представленные данные убедительно свидетельствуют об активном участии различных ПГ в процессах канцерогенеза и их важной функциональной роли в злокачественной трансформации клеток и их микроокружения. Диагностическая, прогностическая и терапевтическая значимость ПГ уже позволила начать практическую разработку новых противоопухолевых препаратов, нацеленных на активацию/ подавление патологической экспрессии таких компонентов опухолевого микроокружения, как декорин [42, 95] и версикан [99].

\section{Внутриклеточные протеогликаны}

ПГ присутствуют также и внутри клетки (помимо биосинтетических этапов), однако это не является их основным местом локализации, и вопрос о структуре, составе и функциях внутриклеточных ПГ остается практически неизученным. Основное место их локализации внутри клетки - секреторные гранулы, и, возможно, они напрямую и/или опосредованно связаны с цитоскелетом.

\section{В нормальных клетках и тканях}

Серглицин является основным ПГ секреторных гранул гемопоэтических клеток, и тесная упаковка белков секреторных гранул зависит от его присутствия [100]. Серглицин содержит такие цепи ГАГ, как ГС, иногда хондроитин или ДС.

Известно, что в человеческих клетках серглицин существует в 2 формах, которые отличаются по функциональным свойствам и, возможно, по составу и/или структуре их углеводных цепей: внутриклеточный серглицин является ключевым медиатором гранулопоэза в тучных клетках, цитолитических Т-лимфоцитах, нейтрофилах и участвует в хранении или секреции протеаз, гистамина, цитокинов и хемокинов в гранулах, а внеклеточный серглицин высвобождается из гранул тучных клеток, цитотоксических Т-лимфоцитов, моноцитов, макрофагов, эндотелиальных клеток и взаимодействует с рецептором CD44 в гемопоэтических клетках. Секреция серглицина вовлечена в высвобождение активатора плазминогена тканевого типа из эндотелиальных клеток, фактора некроза опухолей из макрофагов и матриксной металлопротеиназы 9 из моноцитов [101], что указывает на важную роль серглицина в межклеточных взаимодействиях.

\section{В опухолевых клетках и тканях}

Многочисленные исследования показали, что серглицин, обычно находящийся в секреторных гранулах гемопоэтических клеток (преимущественно тучные клетки и нейтрофилы), секретируется опухолевыми клетками, а в некоторых случаях даже расположен на их мембране [102]. Избыточная экспрессия и секреция серглицина связаны с агрессивностью опухолевых клеток, способствуют их миграции, инвазии и коррелируют с плохим исходом заболевания [103]. Помимо гемопоэтических клеток, серглицин также синтезируется различными типами негемопоэтических клеток (например, эндотелиальными клетками). Его экспрессия также может быть увеличена в опухолях предстательной железы благодаря притоку иммунных клеток к опухоли [83].

Низкие уровни серглицина обнаружены в цитоплазме гиперпластических и нормальных клеток предстательной железы, однако уровень его экспрессии значительно повышен в клетках РПЖ [103]. Повышенная экспрессия серглицина опухолевыми и стромальными клетками усиливает экспрессию медиаторов воспаления, факторов роста и протеолитических ферментов, которые могут действовать аутокринным и/или паракринным способом, влияя на поведение как стромальных, так и эпителиальных клеток. В свою очередь, это может способствовать воспалительному процессу в микроокружении опухолевых клеток, формировать агрессивный фенотип опухоли и придавать устойчивость к химиотерапевтическим препаратам и воздействию системы комплемента [103]. Вполне вероятно, что серглицин участвует таким образом 
в создании опухолевого микроокружения, которое стимулирует рост и распространение опухолевых клеток.

\section{Внутриядерные протеогликаны и гликозаминогликаны}

Наряду с околоклеточной и внутриклеточной локализацией ПГ, они также обнаруживаются и в клеточном ядре, хотя их функции там до сих пор остаются малоизученными.

Первые сообщения, демонстрирующие локализацию ПГ в ядре клеток, относятся к середине 1970-х годов $[104,105]$, когда в клеточных ядрах были идентифицированы различные классы ГАГ - ГС, ДС и/или ХС $[106,107]$. Концентрация, состав и степень сульфатирования ГАГ изучались в очищенных ядрах, выделенных из мозга крыс, где были обнаружены ГС, ХС и гиалуроновая кислота [105], а в ядре и цитозоле сосудистых гладкомышечных клеток аорты крысы внутриклеточный ХСПГ версикан [108]. Основными полисахаридными компонентами ядер клеток меланомы мыши В16 являлись ХС с разной степенью сульфатирования, в то время как ГС был представлен в незначительном количестве [104]. В ядрах нормальной печени мышей были обнаружены ГСПГ и ДСПГ [109], а ядра клеток мышиной гепатомы содержали ГСПГ, ДСПГ и ХСПГ [110].

В целом ГС и ДС были идентифицированы как основные углеводные цепи ядерных ПГ для опухолевых и нормальных клеток печени мышей соответственно, хотя оставалось совершенно непонятным, чем определяется такая гетерогенность состава и содержания ПГ в ядрах различных клеток - методом выделения ПГ (ГАГ), типом клеток или их пролиферативным статусом. Полученные результаты выглядели настолько необычными и не укладывающимися в общепринятые представления о функциональном предназначении ПГ, что не получили должного внимания и развития. Лишь в последнее десятилетие вновь стали появляться работы в этой области исследований, которые приближают нас к пониманию функциональной роли внутриядерных ПГ, связанной с организацией и функционированием клеточного ядра.

\section{Происхождение внутриядерных протеогликанов}

В настоящее время нет определенности в вопросе о происхождении ядерных ПГ [111]. В работе М. Ishihara и соавт. достоверно показано, что по крайней мере часть ядерных ГАГ первоначально была локализована на поверхности клетки и лишь затем транслоцировалась в клеточное ядро [112]. Так, после добавления к культуре гепатоцитов $\left[{ }^{35} \mathrm{SO}_{4}^{2-}\right]$ через 2 ч в ядрах начинал накапливаться $\left[{ }^{35} \mathrm{~S}\right]-$-содержащий ГC, содержание которого достигало равновесного уровня через 20 ч. Терялся этот ГС из ядер с $\mathrm{T}_{1 / 2}=8$ ч. При изучении захвата клетками экзогенного $\left[{ }^{35} \mathrm{~S}\right]-Г \mathrm{C}$ обнаружено, что при температуре $37^{\circ} \mathrm{C}$ клетки захватывали ГСПГ и транспортировали около $10 \%$ интернализованного ГС в ядро, где он появлялся в виде цепей ГАГ, свободных от корового белка [112]. Оценка относительного содержания ГС в клеточном ядре показала, что ядерный пул составляет 6,5 и 5,4 \% от общего количества связанных с клеткой ГС в растущих культурах и культурах, достигших стадии контактного торможения, соответственно [113]. Транслокации подвергаются, по-видимому, не все интернализованные ГАГ, а лишь структурно уникальные ГС - из цитоплазматического пула ГС в ядро транспортируются в основном ГС, обогащенные остатками глюкозы, сульфатированной по 2-му положению (GlcA-2-SO ${ }_{4}^{2-}$ ), в то время как в цитоплазматическом пуле остаются ГС, практически не содержащие GlcA-2-SO ${ }_{4}^{2-}$ [112]. В свою очередь, степень сульфатирования ГС по 2-му положению определяется присутствием в молекуле остатков L-идуроновой кислоты (L-IdoUA). Показано, что экзогенные углеводные цепи ГC, обогащенные L-IdoUA, в отличие от ГС с низким содержанием L-IdoUA, накапливаются в цитоплазме нормальных фибробластов легкого (HFL-1), и временны́е показатели их накопления коррелируют с антипролиферативной активностью этих ГС [114]. В то же время углеводные цепи ГС не появляются ни в цитоплазме, ни в ядрах клеток карциномы легкого (А549) через 24-72 ч инкубации этих клеток с экзогенными ГС.

Возможность транслокации также показана для другого класса ПГ (ДСПГ) в работе D. R. Hiscock и coавт. Они обнаружили, что часть мембранных ДСПГ может захватываться клеткой с последующей транслокацией высвобожденных цепей ДС в клеточное ядро [107].

\section{Функциональная роль внутриядерных \\ протеогликанов}

Несмотря на то что в немногочисленных исследованиях продемонстрировано присутствие ГАГ в ядрах клеток, их функциональное назначение остается малоизученным [115].

Важный момент заключается в том, что благодаря наличию углеводных цепей ГАГ, несущих высокий отрицательный заряд (до 3-4 сульфатных групп/дисахарид) и имеющих очень гетерогенную структуру, молекулы ПГ теоретически способны взаимодействовать с широчайшим спектром других компонентов ядра и влиять на различные внутриядерные процессы. К настоящему моменту получен ряд данных, свидетельствующих о важных регуляторных функциях внутриядерных ПГ, связанных с транспортом различных молекул в клеточное ядро, регуляцией пролиферации клеток и клеточного цикла, структурой хроматина и транскрипционной активностью разных генов.

Транспорт молекул в клеточное ядро. Известно, что ПГ клеточной поверхности играют роль в представлении различных факторов роста для их рецепторов, однако они также, по-видимому, важны для транспорта этих факторов в ядра клеток [111].

Так, показано, что фактор роста фибробластов FGF-2 связывается с ГСПГ и транслоцируется в ядро 
как молекулярный комплекс [116-118], а ГСПГ синдекан 1 колокализуется с FGF-2 в ядре клеток мезотелиомы. Сверхэкспрессия синдекана 1 в этих клетках приводит к увеличению накопления FGF-2 в ядре, что говорит о функциональном значении синдекана 1 для транспорта FGF-2 в ядро [118]. Фактор роста гепатоцитов HGF, связанный с цепями ГС синдекана 1 , секретированного в культуральную среду опухолевыми клетками миеломы, транспортируется в ядра нормальных клеток стромы костного мозга вместе с синдеканом 1 , а удаление связанного с ГС фактора роста гепатоцитов из комплекса отменяет транслокацию синдекана 1 в ядро [115]. Молекулярный механизм такой транслокации в клетках мезотелиомы связан с прямым взаимодействием углеводных цепей ГС с микротрубочками [119], а макромолекулярный комплекс синдекана 1 и тубулина может принимать участие в переносе факторов роста в ядро клетки.

Регуляция пролиферативной активности клеток. Внутриядерные ПГ способны влиять на скорость деления клеток (стимулировать или блокировать его), хотя молекулярные механизмы таких эффектов остаются непонятными. Например, по мере того, как клетки достигают монослоя, выработка ГСПГ в них увеличивается и содержание ГС в клеточном ядре также увеличивается в 3 раза, при этом структура цепей ГС в ядре изменяется - если в активно пролиферирующих клетках внутриядерные ГС содержат в основном 2-О-сульфатированную глюкуроновую кислоту, то при переходе клеток от логарифмического роста к монослою степень сульфатирования ГС в ядре значительно увеличивается и проявляет отрицательную ассоциацию со скоростью деления клеток [113]. Искусственное понижение уровня ядерных ГС приводило к снижению скорости деления клеток и одновременной потере контактного ингибирования, в результате чего наблюдался чрезмерный рост культур, уже достигших стадии контактного торможения [120].

При добавлении к культуре клеток гепатомы, находящихся в логарифмической фазе роста, экзогенных ГСПГ из логарифмически растущих клеток, они захватывались клетками, но очень мало интернализованных ГС появлялось в клеточных ядрах и никаких изменений в скорости роста клеток не наблюдалось. Однако, когда ГСПГ добавляли к клеткам гепатомы, растущим в условиях отсутствия сыворотки и дефицита инсулина, клеточная пролиферация увеличивалась. При добавлении ГСПГ, выделенных из культуры на стадии контактного торможения, рост обработанных клеток тормозился, но возобновлялся при снижении уровня ядерных ГС [121]. По-видимому, ГСПГ из гепатоцитов, находящихся на стадии контактного торможения, играют роль в предотвращении клеточного деления, в то время как ГСПГ из экспоненциально растущих клеток его стимулируют.

Регуляция клеточного цикла. Регуляторные эффекты ядерных ПГ в отношении клеточной пролиферации, по-видимому, тесно взаимосвязаны с регуляцией клеточного цикла и организацией митотического веретена деления. Во время митоза ГС почти полностью исчезали из всех клеточных пулов, а после митоза захватывались и вновь появлялись в ядре, оставаясь там, пока клетки снова не приступят к делению. Добавление ГСПГ к синхронизированным культурам сразу после первого митоза приводило к немедленной остановке клеточного цикла в фазе $\mathrm{G}_{1}$. Ингибирование клеточного роста происходит из-за блока в фазе $\mathrm{G}_{1}$ клеточного цикла до границы $\mathrm{G}_{1} / \mathrm{S}$ [121].

Динамические изменения в структуре глипикана в ядрах клеток глиомы С6 во время деления клеток коррелируют с различными фазами клеточного цикла [122]. Версикан, по-видимому, играет роль в организации митотического веретена деления во время деления эндотелиальных клеток крысы [108], а присутствие синдекана 1 в митотическом веретене деления может стабилизировать митотический механизм в клетках мезотелиомы [119]. Индуцированная винбластином (химиопрепарат, который связывается с тубулином и тормозит образование веретена деления) остановка деления клеток в фазе $G_{2}$ ингибирует транслокацию синдекана 1 в ядро [118].

Все эти данные демонстрируют четкую корреляцию стадии клеточного цикла с ядерной локализацией ГСПГ, но не дают однозначного ответа, регулируют ли внутриядерные ГСПГ клеточный цикл или же стадия клеточного цикла регулирует локализацию ГСПГ в ядре. Этот вопрос требует дальнейших исследований [115].

Влияние на структуру хроматина. Высокий отрицательный заряд углеводных цепей ГАГ позволяет им взаимодействовать с положительно заряженными молекулами внутри ядра, такими как гистоны. В ряде исследований показано, что ГС и ГСПГ действуют как ингибиторы ацетилирования гистонов, тем самым регулируя экспрессию генов. Показано, что ГСПГ, выделенные из роговицы и легочных фибробластов, ингибируют активность гистонацетилтрансфераз р300 и рСAF, а добавление гепарина к легочным фибробластам приводит к быстрому (6 ч) $50 \%$ снижению ацетилирования гистона $\mathrm{H} 3$ in vitro. Способность гепарина ингибировать активность гистонацетилтрансфераз зависела от его размера и структуры; небольшие олигосахариды, полученные из гепарина (>8 сахаров), и $\mathrm{N}$-десульфатированный или О-десульфированный гепарин проявляли сниженную ингибирующую активность [123]. Потеря ядерного синдекана 1 приводит к увеличению степени ацетилирования гистонов (повидимому, за счет активации гистонацетилтрансфераз) и транскрипции генов VEGF, матриксной металлопротеиназы 9, фактора роста гепатоцитов и RANKL при множественной миеломе, что способствует агрессивному поведению опухоли [124].

ГС также играет важную роль в регуляции структуры хроматина во время оплодотворения. В сперме плотная упаковка хроматина обеспечивается протаминами, 
а не гистонами. После оплодотворения ГС облегчают удаление протаминов, что способствует деконденсации хроматина сперматозоида и слиянию мужского и женского генетического материала [125]. ДС и гепарин также способствовали деконденсации хроматина в мышиных сперматозоидах in vitro, но активность гепарина при этом была значительно выше. Использование обоих ГАГ вместе выявило наличие синергетического эффекта. Полученные результаты указывают на новую потенциальную роль ДС в деконденсации хроматина в сперме мышей при оплодотворении [126].

Влияние на топологию ДНК. Помимо влияния на структуру хроматина и степень ацетилирования гистонов, внутриядерные ГАГ способны влиять, по-видимому, на топологию ДНК. ГС из клеток нормальной печени может блокировать активность топоизомеразы I (фермента, необходимого для регуляции релаксации цепей ДНК в ядрах клеток), предотвращая тем самым релаксацию суперспирализованной ДНК. В то же время ГС из неопластической печени человека не влияет на релаксацию сверхспиральной ДНК, свидетельствуя о том, что для блокады топоизомеразы ДНК требуются ГС специфической структуры [127].

В клеточных ядрах ГС могут быть колокализованы с ДНК и нуклеолином - маркером ядрышек, возможно, участвуя в регуляции синтеза и/или высвобождении рибосомной РНК [128] или даже образуя стабильные макромолекулярные комплексы с олигорибонуклеотидами [129].

Взаимодействие с транскрипционными факторами. Помимо изменения экспрессии генов путем модификации структуры хроматина и топологии ДНК, ГАГ (преимущественно ГС) могут взаимодействовать с транскрипционными факторами, влияя на транскрипционную активность различных генов. ГС способны ингибировать взаимодействие транскрипционных факторов, таких как АР-1, SP-1, ETS-1 и ядерный фактор кВ, с их консенсусными олигонуклеотидными последовательностями [130, 131], ДНК-связывающие домены этих транскрипционных факторов содержат последовательности, сходные с белками, которые имеют высокое сродство к гепарину. Интересно, что ГС из прилежащих тканей уменьшал связывание АР-1 и SP-1 с их консен- сусными элементами, а опухолевый ГС не влиял на связывание AР-1 и SP-1 с ДНК, но блокировал взаимодействие ETS-1 с ДНК [131]. Это различие, наблюдаемое между нормальными и трансформированными клетками, может объяснить, как опухолевые клетки экспрессируют гены, способствующие развитию опухоли.

По-видимому, факторы транскрипции чувствительны не только к электростатическому заряду, но также к структурным мотивам, присутствующим в ГС. При связывании с ГС факторы транскрипции могут быть защищены от деградации, тем самым обеспечивается постоянный резерв легкодоступных факторов транскрипции.

Таким образом, присутствие ПГ в ядрах клеток показано в целом ряде работ и получены первые данные о молекулярных механизмах транслокации ГАГ и ПГ в клеточное ядро и тех макромолекулах, которые могут взаимодействовать с ними в ядрах клеток. Пилотные результаты свидетельствуют о важной роли ПГ в функциональной организации клеточного ядра и их потенциальном участии в молекулярных механизмах функционирования генома.

\section{Заключение}

Белково-углеводные молекулы ПГ представляют собой неотъемлемый компонент любой ткани, который играет важную роль как в нормальной физиологии клеток, так и в формировании и поддержании окружающего их ВКМ. Сложная структура ПГ и их высокий отрицательный заряд обеспечивают их взаимодействие с многочисленными лигандами, передачу сигнальной информации, поддержание межклеточных взаимодействий и взаимодействий клеток с их микроокружением. Злокачественная трансформация клеток и тканей тесно ассоциирована с нарушениями в нормальном биосинтезе, локализации и функционировании ПГ, хотя их причинно-следственные отношения остаются на данный момент изучены недостаточно. В этой перспективной области исследований все еще остается больше вопросов, чем ответов, и любые новые результаты безусловно будут вносить важнейший вклад в понимание принципов организации и функционирования живых клеток.

\section{$\begin{array}{lllllllllllllllllllll}\text { Л И } & \text { T } & \text { E } & \text { P } & \text { A } & \text { T } & \text { V } & \text { P } & \text { A } & \text { I } & \text { R } & \text { E } & \text { F } & \text { E } & \text { R } & \text { E } & \text { N } & \text { C } & \text { E } & S\end{array}$}

1. Iozzo R.V. Matrix proteoglycans: from molecular design to cellular function. Annu Rev Biochem 1998;67:609-52. DOI: 10.1146/annurev.biochem67.1.609. PMID: 9759499.

2. Yu P., Pearson C.S., Geller H.M. Flexible roles for proteoglycan sulfation and receptor signaling. Trends Neurosci 2018;41(1):47-61.
DOI: $10.1016 /$ j.tins.2017.10.005. PMID: 29150096.

3. Lindahl U., Couchman J., Kimata K. et al. Proteoglycans and sulfated glycosaminoglycans. Essentials of glycobiology [Internet]. $3^{\text {rd }}$ edn. Cold Spring Harbor (NY): Cold Spring Harbor Laboratory Press, 2015-2017. Chapter 17, 2017. PMID: 28876828.
4. Iozzo R.V., Schaefer L. Proteoglycan form and function: a comprehensive nomenclature of proteoglycans. Matrix Biol 2015;42:11-55. DOI: 10.1016/ j.matbio.2015.02.003. PMID: 25701227.

5. Li J.P., Kusche-Gullberg M. Heparan sulfate: biosynthesis, structure, and function. Int Rev Cell Mol Biol 2016;325:215-73. 
DOI: 10.1016/bs.ircmb.2016.02.009. PMID: 27241222

6. Mikami T., Kitagawa H. Biosynthesis and function of chondroitin sulfate. Biochim Biophys Acta 2013;1830(10):4719-33. DOI: 10.1016/j.bbagen.2013.06.006. PMID: 23774590.

7. Trowbridge J.M., Gallo R.L. Dermatan sulfate: new functions from an old glycosaminoglycan. Glycobiology 2002;12(9):117R-25R. PMID: 12213784

8. Funderburgh J.L. Keratan sulfate: structure, biosynthesis, and function. Glycobiology 2000;10(10):951-8. PMID: 11030741.

9. Afratis N., Gialeli C., Nikitovic D. et al. Glycosaminoglycans: key players in cancer cell biology and treatment. FEBS J 2012;279(7):1177-97. DOI: 10.1111/j.1742-4658.2012.08529.x. PMID: 22333131.

10. Medeiros G.F., Mendes A., Castro R.A. et al. Distribution of sulfated glycosaminoglycans in the animal kingdom: widespread occurrence of heparin-like compounds in invertebrates. Biochim Biophys Acta 2000; 1475(3):287-94. PMID: 10913828.

11. Poulain F.E., Yost H.J. Heparan sulfate proteoglycans: a sugar code for vertebrate development. Development 2015;142(20):3456-67. DOI: 10.1242/ dev.098178. PMID: 26487777.

12. Bernfield M., Götte M., Park P.W. et al. Functions of cell surface heparan sulfate proteoglycans. Annu Rev Biochem 1999;68:729-77. DOI: 10.1146/annurev.biochem.68.1.729. PMID: 10872465.

13. Couchman J.R. Transmembrane signaling proteoglycans. Annu Rev Cell Dev Biol 2010;26:89-114. DOI: 10.1146/ annurev-cellbio-100109-104126. PMID: 20565253.

14. Afratis N.A., Nikitovic D., Multhaupt H.A. et al. Syndecans - key regulators of cell signaling and biological functions. FEBS J 2017;284(1):27-41. DOI: 10.1111/febs. 13940. PMID: 27790852.

15. Choi Y., Chung H., Jung H. et al. Syndecan as cell surface receptors: unique structure equates with functional diversity. Matrix Biol 2011;30(2):93-9. DOI: 10.1016/j.matbio.2010.10.006. PMID: 21062643.

16. Piperigkou Z., Mohr B., Karamanos N. et al. Shed proteoglycans in tumor stroma. Cell Tissue Res 2016;365(3):643-55. DOI: $10.1007 / \mathrm{s} 00441-016-2452-4$. PMID: 27365088

17. Filmus J., Capurro M., Rast J. Glypicans. Genome Biol 2008;9(5):224. DOI: $10.1186 / \mathrm{gb}-2008-9-5-224$. PMID: 18505598.

18. Capurro M., Martin T., Shi W. et al. Glypican-3 binds to Frizzled and plays a direct role in the stimulation of canonical Wnt signaling. J Cell Sci 2014;127(Pt 7): 1565-75. DOI: $10.1242 /$ jcs. 140871 PMID: 24496449.

19. Nicolosi P.A., Dallatomasina A., Perris R. Theranostic impact of NG2/ CSPG4 proteoglycan in cancer. Theranostics 2015;5(5):530-44. DOI: $10.7150 /$ thno. 10824 PMID: 25767619.

20. Yadavilli S., Hwang E.I., Packer R.J. et al. The role of NG2 proteoglycan in glioma. Transl Oncol 2016;9(1):57-63. DOI: $10.1016 /$ j.tranon.2015.12.005 PMID: 26947882.

21. Sakry D., Trotter J. The role of the NG2 proteoglycan in OPC and CNS network function. Brain Res 2016;1638(Pt B): 161-6. DOI: 10.1016/j.brainres.2015.06.003. PMID: 26100334.

22. Morath I., Hartmann T.N., Orian-Rousseau V. CD44: more than a mere stem cell marker. Int $\mathrm{J}$ Biochem Cell Biol 2016;81(Pt A):166-73. DOI: 10.1016/j.biocel.2016.09.009. PMID: 27640754.

23. Jijiwa M., Demir H., Gupta S. et al. CD44v6 regulates growth of brain tumor stem cells partially through the AKT-mediated pathway. PLoS One 2011;6(9):e24217. DOI: 10.1371/journal.pone.0024217. PMID: 21915300.

24. Stanton H., Melrose J., Little C.B. et al. Proteoglycan degradation by the ADAMTS family of proteinases. Biochim Biophys Acta 2011;1812(12):1616-29. DOI: 10.1016/j.bbadis.2011.08.009. PMID: 21914474.

25. Binder M.J., McCoombe S., Williams E.D. et al. The extracellular matrix in cancer progression: role of hyalectan proteoglycans and ADAMTS. Cancer Lett 2017;385:55-64. DOI: 10.1016/j.canlet.2016.11.001. PMID: 27838414.

26. Wight T.N., Kinsella M.G., Evanko S.P. et al. Versican and the regulation of cell phenotype in disease. Biochim Biophys Acta 2014;1840(8):2441-51. DOI: 10.1016/j.bbagen.2013.12.028. PMID: 24401530.

27. Andersson-Sjöland A., Hallgren O., Rolandsson S. et al. Versican in inflammation and tissue remodeling: the impact on lung disorders. Glycobiology 2015;25(3):243-51. DOI: $10.1093 /$ glycob/cwu 120 . PMID: 25371494.

28. Sivan S.S., Wachtel E., Roughley P. et al. Structure, function, aging and turnover of aggrecan in the intervertebral disc. Biochem J 2006;399(1):29-35. DOI: 10.1016/j.bbagen.2014.07.013. PMID: 25065289.

29. Nia H.T., Ortiz C., Grodzinsky A. Aggrecan: approaches to study biophysical and biomechanical properties. Methods
Mol Biol 2015;1229:221-37. DOI: 10.1007/978-1-4939-1714-3_20. PMID: 25325957.

30. Frischknecht R., Seidenbecher C.I. Brevican: a key proteoglycan in the perisynaptic extracellular matrix of the brain. Int J Biochem Cell Biol 2012;44(7):1051-4. DOI: 10.1016/j.biocel.2012.03.022. PMID: 22537913.

31. Chen L., Liao J., Klineberg E. et al. Small leucine-rich proteoglycans (SLRPs): characteristics and function in the intervertebral disc. J Tissue Eng Regen Med 2017;11(3):602-8. DOI: 10.1002/term.2067. PMID: 26370612.

32. Pietraszek-Gremplewicz K., Karamanou K., Niang A. et al. Small leucine-rich proteoglycans and matrix metalloproteinase-14: Key partners? Matrix Biol 2017. DOI: 10.1016/ j.matbio.2017.12.006. PMID: 29253518.

33. Maytin E.V. Hyaluronan: more than just a wrinkle filler. Glycobiology 2016;26(6):553-9. DOI: 10.1093/glycob/ cww033. PMID: 26964566.

34. Pozzi A., Yurchenco P.D., Iozzo R.V. The nature and biology of basement membranes. Matrix Biol 2017;57-58:1-11. DOI: 10.1016/ j.matbio.2016.12.009. PMID: 28040522.

35. McCarthy K.J. The basement membrane proteoglycans perlecan and agrin: something old, something new. Curr Top Membr 2015;76:255-303.

DOI: $10.1016 /$ bs.ctm.2015.09.001. PMID: 26610917.

36. Gubbiotti M.A., Neill T., Iozzo R.V. et al. A current view of perlecan in physiology and pathology: a mosaic of functions. Matrix Biol 2017;57-58:285-98. DOI: 10.1016/j.matbio.2016.09.003. PMID: 27613501.

37. Farach-Carson M.C., Warren C.R., Harrington D.A., Carson D.D. Border patrol: insights into the unique role of perlecan/heparan sulfate proteoglycan 2 at cell and tissue borders. Matrix Biol 2014;34:64-79. DOI: 10.1016/ j.matbio.2013.08.004. PMID: 24001398.

38. Halfter W., Dong S., Schurer B., Cole G.J. Collagen XVIII is a basement membrane heparan sulfate proteoglycan. J Biol Chem 1998;273(39):25404-12. PMID: 9738008

39. Theocharis A.D., Karamanos N.K. Proteoglycans remodeling in cancer: underlying molecular mechanisms. Matrix Biol 2017. DOI: 10.1016/ j.matbio.2017.10.008. PMID: 29128506.

40. Knelson E.H., Nee J.C., Blobe G.C. Heparan sulfate signaling in cancer. Trends Biochem Sci 2014;39(6):277-88. DOI: 10.1016/j.tibs.2014.03.001. PMID: 24755488.

41. Schaefer L., Tredup C., Gubbiotti M.A. et al. Proteoglycan neofunctions: regulation of inflammation and autophagy 
in cancer biology. FEBS J 2017;284(1):

10-26. DOI: 10.1111/febs.13963.

PMID: 27860287.

42. Neill T., Schaefer L., Iozzo R.V. Decorin as a multivalent therapeutic agent against cancer. Adv Drug Deliv Rev 2016;97: 174-85. DOI: $10.1016 /$ j.addr. 2015.10.016. PMID: 26522384.

43. Reed C.C., Gauldie J., Iozzo R.V. Suppression of tumorigenicity by adenovirus-mediated gene transfer of decorin. Oncogene 2002;21(23):3688-95. DOI: $10.1038 /$ sj.onc. 1205470 . PMID: 12032837.

44. Goldoni S., Seidler D.G., Heath J. et al. An antimetastatic role for decorin in breast cancer. Am J Pathol 2008;173(3):844-55. DOI: 10.2353/ajpath.2008.080275. PMID: 18688028 .

45. Du W.W., Yang W., Yee A.J. Roles of versican in cancer biology tumorigenesis, progression and metastasis. Histol Histopathol 2013;28(6):701-13. DOI: $10.14670 / \mathrm{HH}-28.701$. PMID: 23519970.

46. Yoneda A., Lendorf M.E., Couchman J.R. et al. Breast and ovarian cancers: a survey and possible roles for the cell surface heparan sulfate proteoglycans. J Histochem Cytochem 2012;60(1):9-21. DOI: $10.1369 / 0022155411428469$. PMID: 22205677.

47. Theocharis A.D., Skandalis S.S., Neill T. et al. Insights into the key roles of proteoglycans in breast cancer biology and translational medicine. Biochim Biophys Acta 2015;1855(2):276-300. DOI: 10.1016/j.bbcan.2015.03.006. PMID: 25829250.

48. Eshchenko T.Y., Rykova V.I., Chernakov A.E. et al. Expression of different proteoglycans in human breast tumors. Biochemistry (Mosc) 2007;72(9): 1016-20. PMID: 17922662.

49. Yang X., Qiu M., Hu J. et al. Glypican-5 is a novel metastasis suppressor gene in non-small cell lung cancer. Cancer Lett 2013;341(2):265-73.

DOI: 10.1016/j.canlet.2013.08.020. PMID: 23962560.

50. Melo S., Luecke L., Kahlert C. et al. Glypican1 identifies cancer exosomes and facilitates early detection of cancer. Nature 2015;523(7559):177-82. DOI: $10.1038 /$ nature 14581 . PMID: 26106858.

51. Gharbaran R. Insights into the molecular roles of heparan sulfate proteoglycans (HSPGs-syndecans) in autocrine and paracrine growth factor signaling in the pathogenesis of Hodgkin's lymphoma. Tumour Biol 2016;37(9):11573-88. DOI: $10.1007 / \mathrm{s} 13277-016-5118-7$ PMID: 27317256.

52. Tsidulko A.Y., Matskova L., Astakhova L.A. et al. Proteoglycan expression correlates with the phenotype of malignant and non-malignant
EBV-positive B-cell lines. Oncotarget 2015;6(41):43529-39.

DOI: 10.18632 /oncotarget.5984 PMID: 26527314.

53. Hu T.H., Huang C.C., Wu C.L. et al. Increased endostatin/collagen XVIII expression correlates with elevated VEGF level and poor prognosis in hepatocellular carcinoma. Mod Pathol 2005;18(5): 663-72. DOI: 10.1038/modpathol. 3800336. PMID: 15605080.

54. Suhovskih A.V., Aidagulova S.V., Kashuba V.I. et al. Proteoglycans as potential microenvironmental biomarkers for colon cancer. Cell Tissue Res 2015;361(3):833-44. DOI: $10.1007 / \mathrm{s} 00441-015-2141-8$. PMID: 25715761.

55. Baghy K., Tátrai P., Regős E. et al. Proteoglycans in liver cancer. World $\mathbf{J}$ Gastroenterol 2016;22(1):379-93. DOI: $10.3748 /$ wjg.v22.i1.379. PMID: 26755884.

56. Leygue E., Snell L., Dotzlaw H. et al. Lumican and decorin are differentially expressed in human breast carcinoma. J Pathol 2000;192(3):313-20. DOI: 10.1002/1096-9896(200011) 192:3<313::AID-PATH694>3.0.CO;2-B PMID: 11054714.

57. Weber C.K., Sommer G., Michl P. et al. Biglycan is overexpressed in pancreatic cancer and induces G1-arrest in pancreatic cancer cell lines. Gastroenterology 2001;121(3):657-67. PMID: 11522750.

58. Zimina N.P., Dmitriev I.P., Rykova V.I. Composition and degree of sulfation of glycosaminoglycans from tissues of different animal species: heterogeneity and tissue specificity of heparan sulfates. Biokhimiia 1987;52(6):984-90. PMID: 2959327.

59. Суховских А.В., Григорьева Э.В. Тканеспецифичность экспрессии протеогликанов в различных типах опухолей человека. Успехи молекулярной онкологии 2016;3(1):53-60.

[Suhovskih A.V., Grigor'eva E.V. Tissue-specificity of proteoglycans expression in different cancers. Uspekhi molekulyarnoy onkologii $=$ Advances in Molecular Oncology 2016;3(1):53-60. (In Russ.)]. DOI: 10.17650/ 2313-805X.2016.3.1.53-60.

60. Suhovskih A.V., Domanitskaya N.V., Tsidulko A.Y. et al. Tissue-specificity of heparan sulfate biosynthetic machinery in cancer. Cell Adh Migr 2015;9(6):452-9. DOI: 10.1080/19336918.2015.1049801. PMID: 26120938.

61. Kazanskaya G.M., Tsidulko A.Y., Volkov A.M. et al. Heparan sulfate accumulation and perlecan/HSPG2 upregulation in tumour tissue predict low relapse-free survival for patients with glioblastoma. Histochem Cell Biol 2018. DOI: 10.1007/s00418-018-1631-7. PMID: 29322326.
62. Tsidulko A.Y., Kazanskaya G.M., Kostromskaya D.V. et al. Prognostic relevance of NG2/CSPG4, CD44 and $\mathrm{Ki}$ 67 in patients with glioblastoma. Tumour Biol 2017;39(9):1010428317724282. DOI: $10.1177 / 1010428317724282$. PMID: 28945172.

63. Suhovskih A.V., Kashuba V.I., Klein G., Grigorieva E.V. Prostate cancer cells specifically reorganize epithelial cellfibroblast communication through proteoglycan and junction pathways. Cell Adh Migr 2017;11(1):39-53. DOI: $10.1080 / 19336918.2016 .1182292$ PMID: 27111714.

64. Suhovskih A.V., Mostovich L.A., Kunin I.S. et al. Proteoglycan expression in normal human prostate tissue and prostate cancer. ISRN Oncol 2013:680136. DOI: $10.1155 / 2013 / 680136$. PMID: 23691363.

65. Wang D., Anderson J.C., Gladson C.L. The role of the extracellular matrix in angiogenesis in malignant glioma tumors. Brain Pathol 2005;15(4):318-26. PMID: 16389944.

66. Wade A., Robinson A.E., Engler J.R. et al. Proteoglycans and their roles in brain cancer. FEBS J 2013;280(10):2399-417. DOI: $10.1111 /$ febs.12109.23281850. PMID: 23281850.

67. Yao T., Zhang C.G., Gong M.T. et al. Decorin-mediated inhibition of the migration of U87MG glioma cells involves activation of autophagy and suppression of TGF- $\beta$ signaling. FEBS Open Bio 2016;6(7):707-19. DOI: $10.1002 / 2211-5463.12076$. PMID: 27398310.

68. Biglari A., Bataille D., Naumann U. et al. Effects of ectopic decorin in modulating intracranial glioma progression in vivo, in a rat syngeneic model. Cancer Gene Ther 2004;11(11):721-32. DOI: 10.1038/ sj.cgt.7700783. PMID: 15475879 .

69. Arslan F., Bosserhoff A.K., Nickl-Jockschat T. et al. The role of versican isoforms $\mathrm{V} 0 / \mathrm{V} 1$ in glioma migration mediated by transforming growth factor- $\beta 2$. Br J Cancer 2007;96(10):1560-8. DOI: 10.1038/ sj.bjc.6603766. PMID: 17453002.

70. Onken J., Moeckel S., Leukel P. et al. Versican isoform $\mathrm{V} 1$ regulates proliferation and migration in high-grade gliomas. J Neurooncol 2014;120(1):73-83. DOI: $10.1007 / \mathrm{s} 11060-014-1545-8$. PMID: 25064688.

71. Stallcup W. B., Huang F.J. A role for the NG2 proteoglycan in glioma progression. Cell Adh Migr 2008;2(3):192-201. PMID: 19262111.

72. Higgins S.C., Bolteus A.J., Donovan L.K. et al. Expression of the chondroitin sulphate proteoglycan, NG2, in paediatric brain tumors. Anticancer Res 2014;34(12):6919-24. PMID: 25503117.

73. Svendsen A., Verhoeff J.J., Immervoll H. et al. Expression of the progenitor marker 
NG2/CSPG4 predicts poor survival and resistance to ionising radiation in glioblastoma. Acta Neuropathol 2011;122(4):495-510. DOI: 10.1007/s00401-011-0867-2. PMID: 21863242.

74. Lu R., Wu C., Guo L. et al. The role of brevican in glioma: promoting tumor cell motility in vitro and in vivo. BMC Cancer 2012;12:607. DOI: 10.1186/1471-2407-12-607. PMID: 23253190

75. Hu B., Kong L.L., Matthews R.T. The proteoglycan brevican binds to fibronectin after proteolytic cleavage and promotes glioma cell motility. J Biol Chem 2008;283(36):24848-59. DOI: $10.1074 /$ jbc.M801433200. PMID: 18611854

76. Wiranowska M., Ladd S., Smith S.R. et al. CD44 adhesion molecule and neuro-glial proteoglycan NG2 as invasive markers of glioma. Brain Cell Biol 2006;35(2-3): 159-72. DOI: 10.1007/ s11068-007-9009-0. PMID: 17957481.

77. Radotra B., McCormick D. Glioma invasion in vitro is mediated by CD44-hyaluronan interactions. J Pathol 1997;181(4):434-8. DOI: 10.1002/(SICI) 1096-9896(199704) 181:4<434::AID-PATH797>3.0.CO;2-S. PMID: 9196442.

78. Roy A., Attarha S., Weishaupt H. et al. Serglycin as a potential biomarker for glioma: association of serglycin expression, extent of mast cell recruitment and glioblastoma progression. Oncotarget 2017;8(15):24815-27.

DOI: 10.18632/oncotarget.15820. PMID: 28445977.

79. Xu Y., Yuan J., Zhang Z. et al. Syndecan-1 expression in human glioma is correlated with advanced tumor progression and poor prognosis. Mol Biol Rep 2012;39(9): 8979-85. DOI: $10.1007 /$ s11033-012-1767-9. PMID: 22714920

80. Watanabe A., Mabuchi T., Satoh E. et al. Expresson of syndecans, a heparan sulfate proteoglycan, in malignant gliomas: participation of nuclear factor $-\kappa \mathrm{B}$ in upregulation of syndecan-1 expression. J Neurooncol 2006;77(1):25-32. DOI: $10.1007 / \mathrm{s} 11060-005-9010-3$. PMID: 16132527

81. Qiao D., Meyer K., Mundhenke C. et al. Heparan sulfate proteoglycans as regulators of fibroblast growth factor-2 signaling in brain endothelial cells. Specific role for glypican-1 in glioma angiogenesis. J Biol Chem 2003;278(18):16045-53. DOI: $10.1074 /$ jbc.M211259200. PMID: 12591930.

82. Su G., Meyer K., Nandini C.D. et al. Glypican-1 is frequently overexpressed in human gliomas and enhances FGF-2 signaling in glioma cells. Am J Pathol
2006;168(6):2014-26.

DOI: 10.2353/ajpath.2006.050800.

PMID: 16723715.

83. Edwards I.J. Proteoglycans in prostate cancer. Nat Rev Urol 2012;9(4):196-206. DOI: $10.1038 /$ nrurol.2012.19. PMID: 22349653.

84. Kiviniemi J., Kallajoki M., Kujala I. et al Altered expression of syndecan-1 in prostate cancer. APMIS 2004;112(2):89-97. DOI: $10.1111 / \mathrm{j} .1600-0463.2004$. apm1120202.x. PMID: 15056224.

85. Contreras H.R., Ledezma R.A., Vergara J. et al. The expression of syndecan- 1 and -2 is associated with Gleason score and epithelial-mesenchymal transition markers, E-cadherin and beta-catenin, in prostate cancer. Urol Oncol 2010;28(5):534-40. DOI: 10.1016/ j.urolonc.2009.03.018. PMID: 19450993.

86. Shariat S.F., Svatek R.S., Kabbani W. et al. Prognostic value of syndecan-1 expression in patients treated with radical prostatectomy. BJU Int 2008;101(2):232-7. DOI: 10.1111/j.1464-410X.2007.07181.x. PMID: 17868422.

87. Zellweger T., Ninck C., Bloch M. et al. Expression patterns of potential therapeutic targets in prostate cancer. Int J Cancer 2005;113(4):619-28. DOI: $10.1002 / \mathrm{ijc} .20615$. PMID: 15472903.

88. Brimo F., Vollmer R.T., Friszt M. et al. Syndecan-1 expression in prostate cancer and its value as biomarker for disease progression. BJU Int 2010;106(3):418-23. DOI: 10.1111/j.1464-410X.2009.09099.x. PMID: 20002675.

89. Truong Q., Justiniano I.O., Nocon A.L. et al. Glypican-1 as a biomarker for prostate cancer: isolation and characterization. J Cancer 2016;7(8):1002-9. DOI: $10.7150 /$ jca. 14645 . PMID: 27313791.

90. Zhang C., Liu Z., Wang L. et al. Prognostic significance of GPC5 expression in patients with prostate cancer. Tumour Biol 2016;37(5):6413-8. DOI: $10.1007 / \mathrm{s} 13277-015-4499-3$. PMID: 26631038.

91. Warren C.R., Grindel B.J., Francis L. et al. Transcriptional activation by $\mathrm{NF \kappa B}$ increases perlecan/HSPG2 expression in the desmoplastic prostate tumor microenvironment. J Cell Biochem 2014;115(7):1322-33. DOI: 10.1002/ jcb.24788. PMID: 24700612.

92. Grindel B.J., Martinez J.R., Pennington C.L. et al. Matrilysin/matrix metalloproteinase-7 (MMP7) cleavage of perlecan/HSPG2 creates a molecular switch to alter prostate cancer cell behavior. Matrix Biol 2014;36:64-76. DOI: 10.1016/j.matbio.2014.04.005. PMID: 24833109.

93. Grindel B., Li Q., Arnold R. et al. Perlecan/HSPG2 and matrilysin/MMP-7 as indices of tissue invasion: tissue localization and circulating perlecan fragments in a cohort of 288 radical prostatectomy patients. Oncotarget 2016;7(9):10433-47. DOI: 10.18632/oncotarget.7197. PMID: 26862737.

94. Coulson-Thomas V.J., Gesteira T.F., Coulson-Thomas Y.M. et al. Fibroblast and prostate tumor cell cross-talk: fibroblast differentiation, TGF- $\beta$, and extracellular matrix down-regulation. Exp Cell Res 2010;316(19):3207-26. DOI: 10.1016/j.yexcr.2010.08.005. PMID: 20727350.

95. Xu W., Neill T., Yang Y. et al. The systemic delivery of an oncolytic adenovirus expressing decorin inhibits bone metastasis in a mouse model of human prostate cancer. Gene Ther 2015;22(3):247-56. DOI: $10.1038 /$ gt.2014.110. PMID: 25503693.

96. Holland J.W., Meehan K.L., Redmond S.L. et al. Purification of the keratan sulfate proteoglycan expressed in prostatic secretory cells and its identification as lumican. Prostate 2004;59(3):252-9. DOI: 10.1002/pros.20002. PMID: 15042600.

97. Coulson-Thomas V.J., Coulson-Thomas Y.M., Gesteira T.F. et al. Lumican expression, localization and antitumor activity in prostate cancer. Exp Cell Res 2013;319(7):967-81.

DOI: 10.1016/j.yexcr.2013.01.023. PMID: 23399832.

98. True L.D., Hawley S., Norwood T.H. et al. The accumulation of versican in the nodules of benign prostatic hyperplasia. Prostate 2009;69(2):149-58. DOI: $10.1002 /$ pros. 20861 PMID: 18819099.

99. Arichi N., Mitsui Y., Hiraki M. et al. Versican is a potential therapeutic target in docetaxel-resistant prostate cancer Oncoscience 2015;2(2):193-204. DOI: 10.18632/oncoscience.136. PMID: 25859560.

100. Mulloy B., Lever R., Page C.P. Mast cell glycosaminoglycans. Glycoconj J 2017;34(3):351-61. DOI: 10.1007/ s10719-016-9749-0. PMID: 27900574.

101. Li X.J., Qian C.N. Serglycin in human cancers. Chin J Cancer 2011;30(9):585-9. DOI: $10.5732 /$ cjc. 011.10314. PMID: 21880179.

102. Korpetinou A., Skandalis S.S., Labropoulou V.T. et al. Serglycin: at the crossroad of inflammation and malignancy. Front Oncol 2014;3:327. DOI: $10.3389 /$ fonc. 2013.00327 PMID: 24455486.

103. Purushothaman A., Toole B.P. Serglycin proteoglycan is required for multiple myeloma cell adhesion, in vivo growth, and vascularization. J Biol Chem 2014;289(9):5499-509. DOI: 10.1074/jbc.M113.532143. PMID: 24403068. 
104. Bhavanandan V.P., Davidson E.A. Mucopolysaccharides associated with nuclei of cultured mammalian cells. PNAS 1975;72(6):2032-6. PMID: 124440.

105. Margolis R.K., Crockett C.P., Kiang W.L. et al. Glycosaminoglycans and glycoproteins associated with rat brain nuclei. BBA-General Subjects 1976;451(2):465-9. PMID: 999866.

106. Stein G.S., Roberts R.M., Davis J.L. et al Are glycoproteins and glycosaminoglycans components of the eukaryotic genome? Nature 1975;258(5536):639-41. PMID: 128700.

107. Hiscock D.R., Yanagishita M., Hascall V.C. Nuclear localization of glycosaminoglycans in rat ovarian granulosa cells. J Biol Chem 1994;269(6):4539-46. PMID: 8308024.

108. Carthy J.M., Abraham T., Meredith A.J. et al. Versican localizes to the nucleus in proliferating mesenchymal cells. Cardiovasc Pathol 2015;24(6):368-74. DOI: 10.1016/j.carpath.2015.07.010. PMID: 26395512

109. Григорьева Э.В., Рыкова В.И. Ядерные протеогликаны клеток печени мышей: выделение и идентификация. Биохимия 1992;58(8):1165-70. [Grigor'eva E.V., Rykova V.I. Nuclear proteoglycans of murine liver cells: isolation and identification. Biokhimiya $=$ Biochemistry 1992;58(8):1165-70. (In Russ.)].

110. Рыкова В.И., Григорьева Э.В. Состав протеогликанов клеточных ядер гепатомы мыши. Биохимия 1998;63(11):1271-6. [Rykova V.I., Grigor'eva E.V. The composition of proteoglycans of mouse hepatoma cell nuclei. Biokhimiya $=$ Biochemistry 1998;63(11):1271-6. (In Russ.)].

111. Kovalszky I., Hjerpe A., Dobra K. Nuclear translocation of heparan sulfate proteoglycans and their functional significance. Biochem Biophys Acta 2014;1840(8):2491-7.

DOI: 10.1016/j.bbagen.2014.04.015. PMID: 24780644.

112. Ishihara M., Fedarko N.S., Conrad H.E. Transport of heparan sulfate into the nuclei of hepatocytes. J Biol Chem 1986;261(29):13575-80. PMID: 2944884.

113. Fedarko N.S., Conrad H.E. A unique heparan sulfate in the nuclei of hepatocytes: structural changes with the growth state of the cells. J Cell Biol 1986;102(2):587-99. PMID: 2935544.

114. Cheng F., Petersson P., Arroyo-Yanguas Y. et al. Differences in the uptake and nuclear localization of anti-proliferative heparan sulfate between human lung fibroblasts and human lung carcinoma cells. J Cell Biochem 2001;83(4):597-606. PMID: 11746503.

115. Stewart M.D., Sanderson R.D. Heparan sulfate in the nucleus and its control of cellular functions. Matrix Biol 2014;35:56-9. DOI: 10.1016/j.matbio. 2013.10.009. PMID: 24309018.

116. Amalric F., Bouche G., Bonnet H. et al. Fibroblast growth factor-2 (FGF-2) in the nucleus: translocation process and targets. Biochem Pharmacol 1994;47(1):111-5. PMID: 8311835.

117. Hsia E., Richardson T.P., Nugent M.A. Nuclear localization of basic fibroblast growth factor is mediated by heparan sulfate proteoglycans through protein kinase $\mathrm{C}$ signaling.

J Cell Biochem 2003;88(6):1214-25. DOI: $10.1002 /$ jcb. 10470 . PMID: 12647303.

118. Zong F., Fthenou E., Wolmer N. et al. Syndecan-1 and FGF-2, but not FGF receptor-1, share a common transport route and co-localize with heparanase in the nuclei of mesenchymal tumor cells. PLoS One 2009;4(10):e7346. DOI: 10.1371/journal.pone.0007346. PMID: 19802384.

119. Brockstedt U., Dobra K., Nurminen M. et al. Immunoreactivity to cell surface syndecans in cytoplasm and nucleus: tubulin-dependent rearrangements. Exp Cell Res 2002;274(2):235-45. DOI: $10.1006 /$ excr.2002.5477. PMID: 11900484.

120. Ishihara M., Conrad H.E. Correlations between heparan sulfate metabolism and hepatoma growth. J Cell Physiol 1989;138(3):467-76.

DOI: $10.1002 /$ jcp. 1041380305 . PMID: 2522457.

121. Fedarko N.S., Ishihara M., Conrad H.E. Control of cell division in hepatoma cells by exogenous heparan sulfate proteoglycan. J Cell Physiol 1989;139(2):287-94. DOI: $10.1002 /$ jcp. 1041390210. PMID: 2715188

122. Liang Y., Häring M., Roughley P.J. et al. Glypican and biglycan in the nuclei of neurons and glioma cells: presence of functional nuclear localization signals and dynamic changes in glypican during the cell cycle. J Cell Biol 1997;39(4):851-64. PMID: 9362504.

123. Buczek-Thomas J.A., Hsia E., Rich C.B. et al. Inhibition of histone acetyltransferase by glycosaminoglycans. J Cell Biochem 2008; 105(1):108-20. DOI: $10.1002 / j c b .21803$. PMID: 18459114.
124. Purushothaman A., Hurst D. R., Pisano C. et al. Heparanase-mediated loss of nuclear syndecan-1 enhances histone acetyltransferase (HAT) activity to promote expression of genes that drive an aggressive tumor phenotype. J Biol Chem 2011;286(35):30377-83. DOI: $10.1074 /$ jbc.M111.254789. PMID: 21757697.

125. Romanato M., Julianelli V., Zappi M. et al. The presence of heparan sulfate in the mammalian oocyte provides a clue to human sperm nuclear decondensation in vivo. Hum Reprod 2008;23(5):1145-50.

DOI: $10.1093 /$ humrep/den028. PMID: 18287106.

126. Sanchez M.C., Alvarez Sedo C., Julianelli V.L. et al. Dermatan sulfate synergizes with heparin in murine sperm chromatin decondensation. Syst Biol Reprod Med 2013;59(2):82-90. DOI: $10.3109 / 19396368.2012 .756952$. PMID: 23301776

127. Kovalszky I., Dudás J., Oláh-Nagy J. et al. Inhibition of DNA topoisomerase I activity by heparin sulfate and modulation by basic fibroblast growth factor. Mol Cell Biochem 1998;183(1):11-23. PMID: 9655174.

128. Cheng F., Belting M., Fransson L.A. et al. Nucleolin is a nuclear target of heparan sulfate derived from glypican-1. Exp Cell Res 2017;354(1):31-9. DOI: 10.1016/j.yexcr.2017.03.021. PMID: 28300561.

129. Григорьева Э.В., Рыкова В.И. Взаимодействие ядерных протеогликанов с олигорибонуклеотидами. Доклады Академии наук 1997;356(5):693-5. [Grigor'eva E.V., Rykova V.I. Interactions between nuclear proteoglycans and oligoribonucleotides. Doklady Akademii nauk $=$ Proceedings of the Academy of Sciences 1997;356(5):693-5. (In Russ.)].

130. Busch S.J., Martin G.A., Barnhart R.L. et al. Trans-repressor activity of nuclear glycosaminoglycans on Fos and Jun/AP-1 oncoprotein-mediated transcription. J Cell Biol 1992;116(1):31-42. PMID: 1730747.

131. Dudas J., Ramadori G., Knittel T. et al. Effect of heparin and liver heparansulphate on interaction of HepG2-derived transcription factors and their cis-acting elements: altered potential of hepatocellular carcinoma heparansulphate. Biochem J 2000;350(1):245-51. PMID: 10926850. 


\section{Вклад авторов}

А.В. Суховских: обзор публикаций по теме статьи, написание текста рукописи;

Э.В. Григорьева: разработка дизайна исследования, обзор публикаций по теме статьи, редактирование текста рукописи.

Authors' contributions

A.V. Suhovskih: reviewing of publications of the article's theme, article writing;

E.V. Grigorieva: developing the research design, reviewing of publications of the article's theme, editing the article text.

\section{ORCID авторов}

А.В. Суховских: https://orcid.org/0000-0001-5336-8552

Э.В. Григорьева: https://orcid.org/0000-0003-2457-9179

ORCID of authors

A.V. Suhovskih: https://orcid.org/0000-0001-5336-8552

E.V. Grigorieva: https://orcid.org/0000-0003-2457-9179

Конфликт интересов. Авторы заявляют об отсутствии конфликта интересов.

Conflict of interest. The authors declare no conflict of interest.

Финансирование. Исследование поддержано грантом Российского научного фонда (проект № 16-15-10243), написание раздела о внутриядерной локализации протеогликанов поддержано грантом Российского фонда фундаментальных исследований № 15-04-99464.х.

Financing. The study was financially supported by the grant of the Russian Science Foundation (project No. 16-15-10243), the section on intranuclear localization of proteoglycans was supported by the grant of the Russian Foundation for Basic Research No. 15-04-99464.x.

Статья поступила: 10.01.2018. Принята к публикации: 21.02.2018.

Article received: 10.01.2018. Accepted for publication: 21.02.2018. 